(Aus der I. Medizin. Universitätsklinik der Charité [Leiter: Geh.-Rat

Prof. Dr. W. His].)

\title{
Die Zelltheorie des Erythrocyten als Grundlage der klinischen Wertung anämischer Blutbefunde ${ }^{1}$ ).
}

\author{
Von \\ Privatdozent Dr. Vietor Schilling, \\ Assistent der Klinik.
}

Mit 13 Textabbildungen und 8 Abbildungen auf Tafel III.

(Eingegangen am 10. Juni 1921.)

Der Erythrocyt spielt in der klinischen Pathologie eine wichtige, aber im Vergleich zu anderen zelligen Elementen eigentümliche Rolle. Trotz der zahlreichen Veränderungen, die eine immer mehr anwachsende klinisch-histologische Beobachtung am Erythrocyten unter den verschiedensten krankhaften Einwirkungen beschrieb und im allgemeinen als anämische Blutbildveränderungen bezeichnete, blieb das Interesse an einer einheitlichen histologischen Grundlage für die sichere Deutung dieser Strukturen ein geringes. Selbst wenn wir die neuesten hämatologischen Werke nachschlagen, finden wir trotz einer mehr oder weniger vollständigen Aufzählung aller pathologischen Erythrocytenformen oft ein auffallendes und beinahe willkürliches Schwanken in ihrer Beurteilung als ,real" oder „Kunstprodukt", ,e xogen" oder ,endogen", ,regenerativ" oder ,degenerativ", "proto plas matisch"oder ,karyogen". Dabei werden klinische und histologische Bezeichnungen gleichmäßig nebeneinander und durcheinander gebraucht, woraus dann bei den klinischen Folgerungen scheinbare Widersprüche entstehen.

Zum Verständnis sei hier die bekannte baso phile Punktier ung des Erythrocyten genannt. Sie findet sich beim Menschen, wie fast widerspruchslos feststeht, nur bei einigen Anämien irgendwie zahl-

1) Die Arbeit ist als Habilibationsschrift jm März 1920 abgeschlossen und eingereicht worden. Änderungen sind bis auf Korrekturanmerkungen nicht vorgenommen, worauf ich wegen einer Anzahl inzwischen erschienenen Blutplättchenarbeiten (Brieger, Degkwitz, Zeller, Stahl) ausdrücklich àufmerksam mache, da sie teilweise ähnliche Untersuchungen enthalten. Die Drucklegung war wegen der Unterbringung der zahlreichen Abbildungen bei anderen Zeitschriften erschwert. 
V. Schilling: Die Zelltheorie des Erythrocyten als Grundlage usw. 549

reicher, in erster Linie Malaria, Bleikrankheit, Wurmanämien, einigen hämolytischen Prozessen, kurz bei toxisch zu erklärenden Blutschädigungen. Anfangs erschienen diese isolierten und scharfen blauen Pünktchen in den Erythrocyten so besonders, daß man an exogene Einlagerungen (Bleiverbindungen, selbst Malariadauerformen) denken wollte. Die unverkennbare allgemeine Blutalteration dieser Krank: heiten legte natürlich zuerst den Gedanken einer degenerativen Veränderung der Erythrocyten nahe und man bemühte sich, durch Versuche am abgebundenen GefäB und in vitro die direkte Umwandlung der Erythrocyten in die basophilpunktierten zu zeigen. Weiterhin errang sich dann vor allem durch klinische Beobachtungen, die das Auftauchen der Punktierung mit den ersten Stadien frischer Blutregeneration besonders reichlich zeigten, und durch die karyogene Theorie, die die Entstehung aus Kerntrümmern lehrte, die regenerative Wertung so sehr den Vorrang, daß Naegeli²) sie heute als feststehend anführt. Daß dieses ,,regenerativ" jedoch für die meisten Autoren nur eine klinische Vorstellung sein kann, ergibt sich aus dem Streit der Meinungen um die karyogene oder protoplasmatische Entstehung, die jede für sich die besondere Erscheinungsform aus der Zertrümmerung entweder des Kernes der Vorstufen oder des basischen Protoplasmas polychromer Erythrocyten herleiten, also beide unzweifelhaft $h$ is tologische Degenerationen beschreiben. Gerade die moderneren Anhänger der karyogenen Theorie haben diesen Widerspruch gefühlt und eben den Vorgang der Zertrümmerung als einen auch regenerativen beweisen wollen, indem sie ihn als embryologisch vorkommend (Engel), als vielleicht mitotisch erzeugt (Naegeli) oder durch Ausstoßung blauer Plastinmassen aus intakten Kernen (Ferrata) erklärbar bezeichneten. Damit ist natürlich nicht viel gewonnen, da selbst im Embryo massenhaft Prozesse vorkommen, die zellulär nur Degenerationen sind und mit der Rückbildung ganzer Zellgeschlechter zusammenhängen.

Die Heranziehung klinischer ,Beweise“ kann in diesen ausgesprochen histologischen Fragen nur störend wirken, während die histologische Festlegung des Vorganges oder der Form in ihrer Beziehung zum normalen Erythrocyten eine absolut bindende Grundlage abgeben kann, mit der sich die klinischen Feststellungen dann ins Einvernehmen zu setzen haben und damit ein festes Rückgrat für dieklinische Wertung erlangen. Wir werden später sehen, daß dieses Beispiel durch die histologische Lösung als ,degenerative Abbauform jugendlicher. Polychromasie" klinisch einleuchtend aufgeklärt ist: basophile Punktierung ist eine geschädigte Regenerationsform des Erythrocyten, diebei physiologischer Regeneration zu fehlen pflegt, nicht mit Normoblasten, sondern mit 
Polychromasie parallel geht und wegen ihrer histologischen Besonderheit die Anämien diagnostisch und prognostisch wertvoll in normal und gestört regenerierende teilt. (Verfasser zu Klien eberger ${ }^{7}$ ).

Die Ursache der geschilderten Unsicherheit in der Beurteilung der Erythrocytenstrukturen liegt in dem Fehlen einer anatomisch anerkannten Lehre vom Bau des Säugetiererythrocyten. Während dieser für den Kliniker ein sehr wertvolles und notwendiges Studienobjekt war, gingen die Histologen gern der kleinen schwer zu behandelnden, der Fülle lohnender Objekte gegenüber zurücktretenden Blutzelle aus dem Wege. Dazu hatte die Physiologie in der Betonung der allein funktionellen Bedeutung des kernlosen Hämoglobinträgers den Mangel einer zellartigen Struktur nicht allzusehr fühlen lassen, denn hierfür reichte scheinbar ein durch eine Membran geschützter Hämoglobintropfen schon aus.

In der Tat bewegte sich die letzte umfassende Beschreibung des Erythrocyten von anatomischer Seite durchaus in diesem Rahmen. Unter Abweisung der meisten im Laufe der Zeit doch hervorgetretenen, wenig beachteten Schilderungen komplizierterer Strukturen (Boettcher, Kollmann, Bremer, Arnold, Giglio-Tos, Maximow, Pappenheim, Hirschfeld u. a.) lehrte Weidenreich ${ }^{6}$ ): der Erythrocyt der Säuger istein Bläschen aus Membran und Endosoma mit einem häufig noch nachweisbaren letzten punktförmigen Kernrest; alles andere sind Pseudostrukturen, Membrandifferenzierungen, exogene Niederschläge usw.

Es ist allerdings fraglich, ob durch den negativen Erfolg technischer Darstellung überhaupt so zwingende Versuche wie die Rolletts und Ha mburgers widerlegt werden konnten, die durch den Augenschein zertrümmerten Erythrocyten oder durch das Verhalten bei osmotischen Vorgängen eine durch und durch plas matische Beschaffenheit (Heidenhain ${ }^{8}$ ) der Er y throc yten scheibe viel glaubhafter machten. Sicher aber war, daß diese einfache Auffassung den schwierigeren Strukturen der Nucleoide, Innenkörper usw. stark Abbruch tat.

In diesem Stadium der Frage wurde vom Verfasser ${ }^{4}$ ) auf Grund umfangreicher Voruntersuchungen eine neue umfassende Erythrocytentheorie aufgestellt, die es sich bewuBtzur Aufgabe machte, alle die zahlreichen sehr verschieden beschriebenen und gewerteten Strukturen im roten Blutkör perchen unter dem Gesichtspunkteiner regelrechten Zellstruktur zu identifizieren, ihren Ursprung abzuleiten und ihre feste Wertung zu ermöglichen, indem sie analoge Veränderungen in anderen Zellen heranzog (Verfasser ${ }^{4}$ ) Arb. 7). 
Das Wesentliche dieser Theorie, deren Ausbau und deren klinische Nutzanwendungen im Folgenden zusammenfassend geschildert werden sollen, ist:

a) Der Erythrocyt ist im Prinzip eine wirkliche Zelle wie jede andere, aber fortschreitend stark modifiziert. Als junge Zelle besitzt er, vielleicht histologisch teilweise schwer zu zeigen, alle Elemente menschlicher Körperzellen, soweit sie prinzipiell zur Zelle gehören.

b) Der reifende Erythrocyt besitzt diese Zellorgane noch, selbst wenn sie technisch nicht immer darzustellen sind, und anscheinend

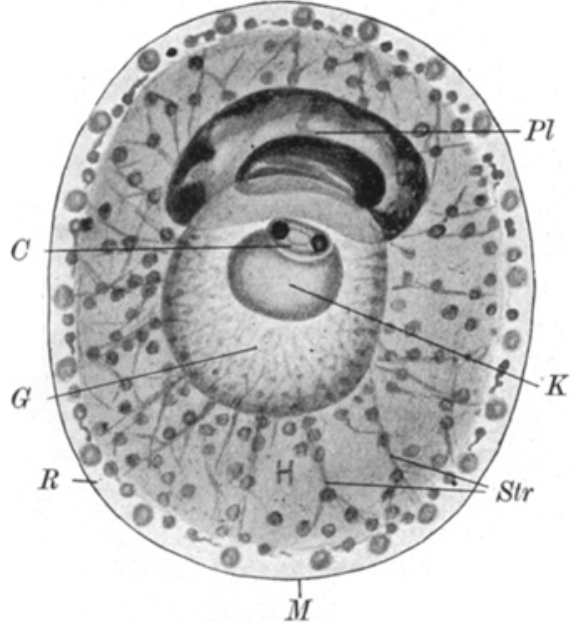

Abb. 1 a. Theoretisches Schema der Erythrocytenstruktur. $P l=$ Plättchenkern; $G=$ Glaskörper; $K=$ Kapselkörper ; $H=$ Hämoglobinteil ; $C=$ Centrosom; $R=$ Zwischenraum; $\boldsymbol{M}=$ Physiologische Membran.
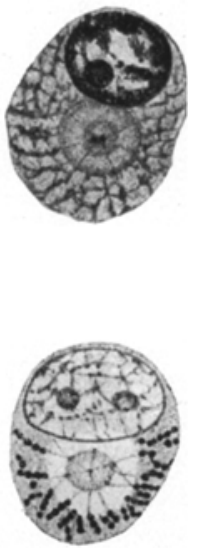

Abb. 1 b. Plasmazellenstruktur nach Axel Walgreen zum Vergleieh. ${ }^{1}$ )

neu auftauchende Strukturen müssen in erster Linie durch $A$ b wa nd l ung der elementaren Strukturen erklärt werden.

c) Die Zellauffassung erlaubt es, analoge Strukturen in besser technisch zu verarbeitenden gröBeren Körperzellen vergleichsweise heranzuziehen, wenn die Ableitung bei der Rückverfolgung in der Erythrocytenstammreihe nicht gelingen will.

d) Als derartige Grundstrukturen wurden aufgefaßt (Abb. 1):

1. der Kern, bzw. Kernrest (Abb. 1, Bl. PI.)

2. das Proto plas ma, bestehend aus Ekto-, Endoplasma und spezifischen Protoplasmaerzeugnissen (Abb. 1, M.H. R. Str.),

3. das Archo plas ma, bestehend aus Centrosom (C), Sphärenteil $(G)$ und besonderen Archoplasmagebilden von der Art der Golgi-Körper usw. zusammengefaßt als Kapselkörper $(K)$.

1) Beitr. z. pathol. Anat. 1911, 52. Abb. 7 u. 20 der Taf. VII. 
Daß eine so komplizierte Auffassung durchaus im Bereich der Möglichkeit Iag und nicht ohne weiteres unter die Pseudostrukturen $z u$ verweisen war, bewiesen die gut übereinstimmenden Beschreibungen älterer Autoren, die schon zwischen einer wesentlich verschiedenen peripheren und einer zentralen Schicht unterschieden, teilweise unter genauer Angabe scharf begrenzter Innenkörper (Bre mer) oder weniger scharf begrenzter "Nucleoide" (Arnold, Maximow, Hirschfeld, Pappenheim), die sie je nach ihrer Auffassung als protoplasmatisch oder karyogen ansahen. Auch kam Axel Wallgren (Abb. 1b. l.c.) ganz unabhängig und etwa gleichzeitig zu einem ähnlichen Strukturbild der Plasmazellen.

Das eigentlich Neue der Theorie liegt in ihrer komplexen praktischen Auswertung und in der strengen Scheidung zwischen wirklichen und scheinbaren Kernresten, die durch die Modifikation der Blutplättchentheorie und die Einführung des dritten, des archoplasmatischen Zellbestandteiles, möglich wurde.

Wenn wir im folgenden die klinischen Befunde mehr in den Vordergrund stellen, so geschieht dies nicht, um dadurch die Richtigkeit dieser Theorie weiter zu erweisen. Vielmehr hat sich immer wieder gezeigt, daB die Vieldeutigkeit klinischer Beobachtungen die widersprechendsten histologischen Theorien scheinbar überzeugend zu stützen erlaubt. Immerhin dürfen aber auch in den Einzelheiten keine auffallenden und unerklärbaren Widersprüche zu klinischen Notwendigkeiten entstehen. Mit dieser Einschränkung darf dann auch wohl die vielseitige und ungezwungene klinische Anwendbarkeit insgesamt als eine Stütze für die Richtigkeit und Notwendigkeit der histologischen Theorie angegeben werden, die z. B. von T ürk bereits nach der vorläufigen Mitteilung anerkannt wurde. (Klin. Vorlesungen Bd. 2, S. 176).

\section{Kernstrukturen.}

\section{a) Normale Kerne. [Abb. 21).]}

Seit Neumanns Entdeckung der gekernten Knochenmarksformen des Säugetiererythrocyten sind normale Erythro- und Normoblasten im peripheren Blute wohl ausnahmslos als histologische Regenerationserscheinungen beschrieben und klinisch gewertet worden. Sie finden sich bei allen schweren Anämien außer der aplastischen, beim Weibe leichter als beim Manne, beim Kind viel leichter als beim Erwachsenen infolge lebhafterer Reaktion der Erythropoese.

Bemerkenswert in unserem Sinne ist, daß Kerne reiferer Erythrocyten durchweg kleiner, chromatinreicher, zuletzt fast flüssig

1) Abb.2 war ursprünglich buntes Aquarell, ist erst bei der Drucklegung durch Mikrophotogramme ersetzt: 
pyknotisch erscheinen und fast stets exzentrisch, augenscheinlich sehr oberflächlich z a m Hb-Kör per liegen. Selbst noch gut strukturierte Radkerne jüngerer Vorstufen werden außerordentlich leicht und ohne jede Schädigung des Hb-Teiles, der kernlos bestehen bleibt, enucleiert, ohne daß ein Kernrest $z$ ur ückbleibt. Fin feines Körnchen von azurophiler Rotfärbbarkeit liegt dabei von vornherein paranucleär und bildet häufig beim Austritt zarte Fasern zwischen Kern und Plasma aus. Hiermit werden wir uns jedoch erst

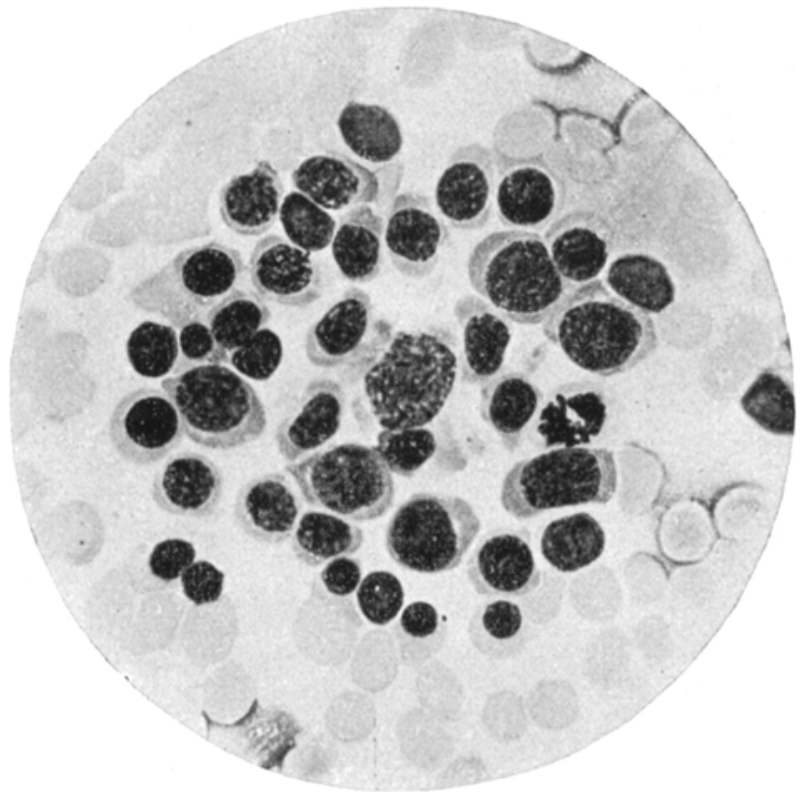

Abb. 2. Erythroblastengruppe aus embryonalem Blut, Menschlicher Foetus vom 4. Monat, Verwandlung der strukturierten großen Kerne der Stammzellen in immer kleinere, dunklere und exzentrische Normoblastenkerne (unten und links). Mikrophotogramm; Giemsa-Ausstrich. präparat.

weiter unten zu befassen haben. In ganz jugendlichen Zellen befinden sich Mitosen und Vor- und Nachstadien derselben, ohne daß man meiner Kenntnis nach normal je eine Absplitterung von roten chromatischen Massen sieht; dagegen bleibt unmittelbar nach dem Diaster oft ein Zwischenfaden von.chromosomenartigem Aussehen zwischen den wieder gerundeten Kernen als paranucleäres, rundlich zusammenschnurrendes Gebilde liegen. Aus dieser Karyodesmose bilden sich wahrscheinlich die unten zu besprechenden Jollykörper oder Kernkugeln. In reifen Zellen tritt nicht selten eine gewisse Polymorphie der Kernform (Bisquit-, Kleeblatt-, selten Rosetten- und Wurstform) hervor, kann aber auch bei lebhaftester Erythropoese ganz fehlen (Abb. 2) 
Unzweifelhaft sind klinisch alle diese Erscheinungsformen, trotzdem sie histologisch einen fortschreitenden Abbars der Kerne deutlich. zeigen, als regenerative Erscheinungen im Blutbild zu werten, da sie als normale Entwioklungsstadien der Erythrocyten zu bezeichnen sind.

Dennoch erfordert die klinische Folgerung aus dem Befunde von Kernresten schon einige Vorsicht, da im klinischen Sinne sehr wohl mehr als eine physiologisch verstärkte Regeneration, ja sogar eine entgegengesetzte pathologische Störung des Knochenmarkorganes vorliegen kann. Hier haben die Hilfsmethoden der Zählung, des Leukocytenbildes, der klinische Status klärend zu wirken. Solche Fälle sind:

a) Insuffizienz des Knochen markes, seine Zellen bis zur Reife festzuhalten, wie schwere Reize, agonale Ausschwemmung usw.

b) Verdrängung der unreifen Ele mente durch Tumoren, Osteofibrose, Leukämien oder leukocytotische Hyperplasien.

c) Bildung extra med ullärer Er y thro poese oder pathologischer Hyperplasie der Erythroblastenherde wie bei Polycythämie.

Alle die hieraus resultierenden Erythrocytenbilder sind prinzipiell gleich, und vom Standpunkte des Hämatologen scheint es mir verfehlt, sie sogleich nach dem Blutbilde ätiologisch und theoretisch einteilen $\mathrm{zu}$ wollen. Das Wesentliche ist stets das Auftreten der einwandfrei unreifen kernhaltigen Jugendform des Erythrocyten; ich 4 a habe daher diese Blutbilder als normoblastisches Erythrocytenbild prinzipiell zusammengefaßt, da sio im peripheren Blut histologisch in der Tat eine untrennbare Einheit bilden.

Sache der Klinik ist es dann, durch die erwähnten weiteren Symptome die Ursache des normoblastischen Erythrocytenbildes zu bestimmen:

1. Physiologische verstärkte Regeneration (einfache, aber hoch gradige Anämien).

2. Pathologische Ausschwemmung,

a) Insuffizienz des Knochenmarkes.

b) Verdrängung im Knochenmark.

c) Hyperplasie.

d) Extramedulläre Erythropoese.

Natürlich können klinisch auch mehrere Ursachen gleichzeitig wirken.

Gerade dieses Beispiel habe ich hier ausführlicher konsequent durchgeführt, da es zeigt, wie selbst ein histologisch ganz eindeutiger Befund mehrere Möglichkeiten der Wertung zuläßt. Zu einer unerträglichen Verwirrung aber muß es führen, wenn einige Autoren entgegen allen Beobachtungen an sonstigen differenzierten Körperzellen das Sichtbarwerden von neuen Kernen in kernlosen extravasierten Erythrocyten usw. für möglich erklären, oder aus der Vielheit klinischer 
Deutungen willkürlich eine herausgreifen, um den histologischen Befund klinisch zu werten. Wer z. B. von der schweren Anämie der Osteosklerosen aus, die klinisch tatsächlich eine Degeneration der ganzen Erythropoese bewirken, nun die dabei vorkommenden normalen kernhaltigen Ausschwemmungsformen für degenerierte Erythro. cyten erklären wollte, beginge einen fundamentalen Fehler, der nichtsdestoweniger bezüglich der Polychromasie, der basischen Netzstruktur und anderer Erscheinungen am Erythrocyten oft gemacht und sehr schwer wieder auszutilgen ist.

\section{b) Pathologische Kerne.}

Nach der herrschenden Auffassung der Hämatologie sind die Kerne der Megaloblasten anders strukturiert beschrieben als die Normoblastenkerne, und zwar sollen die ersteren auch hierin mit den embryonalen Zellen übereinstimmen (Ehrlich, Pappenheim, Naegeli u. a.).

Von versehiedener Seite, u. a. von $\mathrm{Pa}$ p pen hei $\mathrm{m}$, ist jedoch bereits der theoretisch sehr interessante Versuch gemacht worden, die von Ehrlich angenommene und heute noch fast durchgehends anerkannte prinzipielle Trennung zwischen Erythrocyten des Embryos und des ausgetragenen menschlichen Körpers durch Beschreibung von Zwischenstufen zu überbrücken. Das ist jedoch im allgemeinen als gescheitert anzusehen ( $\mathrm{Naegeli}{ }^{2}$ ).

Histologisch erscheint das Problem jedoch durchaus lösbar, wenn man den Übergang von normalen Epithelzellen in gänzlich entartete Krebszellen heranzieht oder die vollkommenen Entartungen mancher leukämischer Vorstufen berücksichtigt. Es ist sehr wohl denkbar, daß unter besonderen Anforderungen, wie sie der gleichzeitig reizende und vergiftende Einfluß der Ursachen, die zum perniziösen Blutbild führen, vermuten läßt, die Kernplasmarelationen der jüngsten an sich großen Erythrogonien sich so verändern, daß bei relativ sehr unreifem Kern bereits beginnende oder vollendete $\mathrm{Hb}$-Bildung vorliegt. In diese $\mathrm{m} \mathrm{Falle}$ w ürde die Mega loblastose eine zelluläre Entartung, nicht aber eine prinzipiell neue (,embryonale") Er ythrocytenart bedeuten, wodurch die schon stark erschütterte Sonderstellung des megaloblastischen Blutbildes weiter eingeschränkt würde. Es würde sich dann nur um eine em bryoide, nicht um eine embryonale Umwandlung handeln. Da hierüber noch keine beweisenden Untersuchungen vorliegen, werde ich diese Frage erst weiter unten bei der Plasmastruktur besprechen.

Klinisch ist, wie allgemein bekannt ist, der pathologische Megaloblastenkern ein sehr wichtiges diagnostisches Mittel zur Unterscheidung von den großen Erythroblasten. 
Bei dem Abbau des Megaloblastenkernes begegnen wir viel häufiger einer Form der Kernzertrümmerung, die als $K$ ar yorr he $\mathrm{x}$ is bezeichnet wurde (Rindfleisch). Dieser Prozeß kann mit Karyolyse verbunden sein, aber auch bis zu weitgehender Zerteilung der Kernbröckel obne Karyolyse führen. Die mit Kernbröckeln erfüllten Zellen sind dann bei ungeeigneten Methylenblau- und Hämatoxylinfärbungen mit den basophilpunktierten kernlosen Erythrocyten verwechselt worden, während eine Giemsafärbung durch die azurophile Rotfärbung aller Kernbröckel einen scharfen Unterschied gegenüber der echten blauen (protoplasmatischen) Punktierung erweist. (Azurophile Punktierung von Ferrata und Viglio ${ }^{10}$ ), Naegelia) u. a.).

Außer diesen multiplen Brocken sind besonders runde pyknotische, meist in der Einzahl vorhandene Kern $\mathrm{k} u$ geln von Howell, Joll y u, a. beschrieben worden, die in letzter Zeit von $\mathrm{Nägeli}^{2}$ ), Pa p penhei $\mathrm{m}^{3}$ ) $u$. a. als ein normales $Z$ wischen produkt vom Nor moblastenkern zu sehr kleinen fast punktförmigen Gebilden bezeichnet und besonders von Weidenreich ${ }^{6}$ ) unter dem Namen , Randkörnchen ${ }^{6 *}$ als letzter Kernrest im Erythrocyten angesehen wurden. "Sie entstehen wahrscheinlich pathologisch vermehrt aus unvollkommener Rückbildung der Karyodesmose nach der Mitose (s. oben).

Die einzige Lösung in der Wertung aller dieser Gebilde ist die Aufklärung des normalen Entkernungsprozesses, denn selbstverständlich sind nur die Strukturen als pathologisch zu verwerten, die nicht in die normale Entkernung hineingehören.

Utber diesen histologisch bisher völlig unklaren Prozeß verzeichnet z. B. Pappenheim ${ }^{3}$ ) drei Ansichten:

a) normale postpyknotische Chromatinolyse (letzter Rest die Howell-Joll y-Körper),

b) pathologische Karyorrhexis,

c) nur im Blut vorkommende Plasmolyse mit freiwerdenden Kernen.

Die älteren Ansichten gingen hin und her zwischen der Rind fleischschen Kernausstoßung (Enucleation) und der Köllicker-Neumannschen intrazellulären Karyolyse, für die besonders IsraelPappenheim durch Besehreibung der abblassenden Kernformen im Knochenmark kaum ganz einwandfreie Bilder geliefert hatten.

Nach den neuesten Ansichten verläuft die Entkernung durch Chromatinolyse des zuerst pyknotiseh gewordenen und. verkleinerten Nor moblastenkernes, wobeinach $\mathrm{Pa}$ penheim zuletzt nur noch das eosinfärbbare Oxychromatin in der Delle b leiben soll. Wie sich nun dabei die kleine dunkle Zwischenform des Jollykörpers ausbilden soll, bleibt bei Pa p penheim ganz unverständlich. Die übrigen Autoren (Jolly, Weidenreich, Naegeli u. a.) lassen den Kern in der Tat sich einfach weiter verkleinern, wobei nach 
Weidenreich auch große Chromatinteile nach außen abgestoßen werden und schließlich in die erwähnten punktförmigen Kernreste übergehen, die nach Naegeli bleiben, nach Weidenreich auch in das Plasma wandern.

Höchst merkwürdig ist nun, daß man von diesem ganzen Prozeß, der sich doch wegen der leichten Darstellbarkeit der Jollykörper ohne weiteres histologiseh zeigen lassen müßte, in den allerbesten Frischpräparationen des Knochenmarkes anämisierter Versuchstiere (feuchte Giemsa-Methode) nicht das Geringste zu sehen bekommt, wenn nicht schwere Störungen der Erythropoese vorliegen. Die großen Massen der Normoblasten liegen mit allen Kernabstufungen vom großen Radkern mit Mitosen bis zum kleinen innerlich ganz verflüssigten exzentrischen Pyknose-Kern auf das Schönste im Material ausgebreitet und dabei gehören Howell-Kör per zu den größtenSeltenheiten. (Vgl. Abb. 2.) Auch im peripheren Blut fehlen sie trotz enormer Regeneration unter Umständen gänzlich. Am seltensten sind sie beim Menschen, und hier sind sie von $\operatorname{Schur}^{9}$ ), Morris ${ }^{10}$ ), $\operatorname{Roth}^{11}$ ) u. a. als sehr auffallender Befund besonderer Fälle beschrieben worden. Als eine Ursache für ihr Auftreten hat Roth, bestätigt von Hirsch feld und Weiner $t^{13}$ ), Karlba $\mathrm{m}^{14}$ ) u. a. die Milzausschaltung durch pathologische Prozesse oder Splenektomie erkannt. Vereinzelt kommen sie allerdings bei vielen toxischen Anämien vor. Die Weidenreichschen Randkörnchen, die Dehler, Nissle u. a. schon bekannt waren, sind dagegen als regelmäßiger Bestandteil der Erythrocyten auch durch die Ultra-Photogramme Grawitz-Grünbergsis) und die Untersuchungen des Verfassers ${ }^{7}$ ) bestätigt.

Zwischen diesen Körnchen und den immerhin doch noch etwa ein Drittel bis ein Viertel Durchmesser des Erythrocyten einnehmenden verkleinerten pyknotischen Kernehen klafft ein durch die vorgetragenen Auffassungen unerklärlicher Sprung, der sich aber durch die nachfolgende Blutplättchenableitung sehr einfach lösen w ürde.

Nach den vorliegenden Ergebnissen können wir histologisch in Kernbröckeln und Howell-Joll y-Körpern nur pathologische Kernreste erblicken, deren Auftauchen nach Splenektomie klinisch im Sinne von Hirschfeld als eine durch Ausfall hormonaler Milzprodukte gestörte Entkernung im Knochenmark ganz befriedigend erklärt würde.

Diesen pathologischen Kernresten sind vielleicht auch die von Cabot, Schleip u. a. beschriebenen Innenreifen oder -schleifen in Erythrocyten anzureihen, die allgemein als Kernwandverdichtungen gedeutet sind, ebenso die azurophile Polychromasie $\left[\mathrm{Naegeli}{ }^{2}\right)$, Ferrata u. Viglio $)$ ]. Es ist aber auch nicht ausgeschlossen, daß die Cabot-Ringe dem Randreifen der kernhaltigen Erythrocyten ent- 
sprechen und damit als Protoplasmastrukturen hier aus der Betrachtung ausscheiden ( $\mathrm{Nis}$ isle, Verfasser).

Erst wenn die Entstehung aller dieser Kernreste klargestellt sein wird, können wir mit mehr Sicherheit kiinisch sie für Re- oder Degeneration verwerten, was z. B. für Kernkugeln z. Z. noch ganz strittig bleiben muß.

Manches ergibt sich von selbst mit dem Beweis der folgenden Plättchenkerntheorie.

Für den Austritt der pathologischen Kernform aus dem Knochenmark gelten klinisch dann noch die allgemeinen Erwägungen, die wir für das Auftreten von Kernbaltigen überhaupt anstellten.

\section{c) Plättchenkerne.}

Nach Pappenheim ${ }^{3}$ ) wird normalerweise im Anschluß an eine vorausgegangene Pyknose der Erythroblastenkern in einem gewissen Stadium plötzlich ausgelaugt (Chro matinolyse). Zurück bleibt ein plastinisch hellblau, zuletzt oxyphiles Innenkörperchen im kernlosen Erythrocyten, das er mit Arnold, Hirschfeld, Maximow ${ }^{17}$ ) u. a. als überbleibenden Kernrest oder Nucleoid beschrieb und mit dem auch in reifen Erythrocyten nachweislichen Innenkörper einerseits, mit dem freiwerdenden Blutplättchen andererseits in Verbindung brachte. Unzweifelhaft sind die eigentlichen Nucleoide, die man z. B mit der Reddingiusschen Färbung technisch darstellen kann, etwas ganz anderes, das Verfasser zu den Archoplasmastrukturen überwies (s. dort). Dagegen würde ein ausgelaugter Kern tatsächlich mitseinenletzten Chromatinspuren und seiner schwach-basischen Grundsubstanz durchaus ein Blutplättchen des Ausstrichpräparates vorstellen können. Preisich und Heim ${ }^{18}$ ) haben diese Gedankenreihe fortgesetzt und glaubten sie histologisch durchführen zu können, doch klafft zwischen ihren angeblich abgeblaßten Kernen und den sehr kleinen und stark hell gehöften Blutplättchen auf ihren Abbildungen eine Kluft, die eben nicht allzu überzeugend wirkt. Auch Enge ${ }^{20}$ ), Helber ${ }^{21}$ ), Grawitz 22 ), Brockbank ${ }^{23}$ ) u. a. haben die Ableitung der Blutplättchen von Erythroblastenkernen versucht; m. E. aber mit den abgebildeten Haufen von Blutplättchen aus einem Erythrocyten (Granaten) und der Trockenausstrichmethode nur zufällige Anklebungen vor Augen gehabt.

Gewissermaßen eine Fortsetzung und doch eine neue beweiskräftigere Vorstellung brachten Untersuchungen des Verfassers ${ }^{4}$ ) mit besonderen Schnellfixierungen von absolut ungeschädigtem Blut, das durch paraffinierte Capillaren direkt aus dem Blutgefäß in Domi- 
nici-Fixativ (Jod-Sublimat) gesogen und später nach der Giemsa-Feuchtfärbung weiter behandelt wurde (Abb. 3).

Die Blutplättchen erschienen nun als pyknotische stark chromatinhaltige, aber auch oft noch deutlich strukturierte Kernchen einer gewissen Anzahl jüngerer Erythrocyten, an oder in denen sie meist exzentrisch, isoliert oder ganzselten zu zweien lagen. Allerdings schien das Chromatin sich in einem für Hämatoxylin nur noch schwer färbbaren weitgehenden Lösungszustande zu befinden.

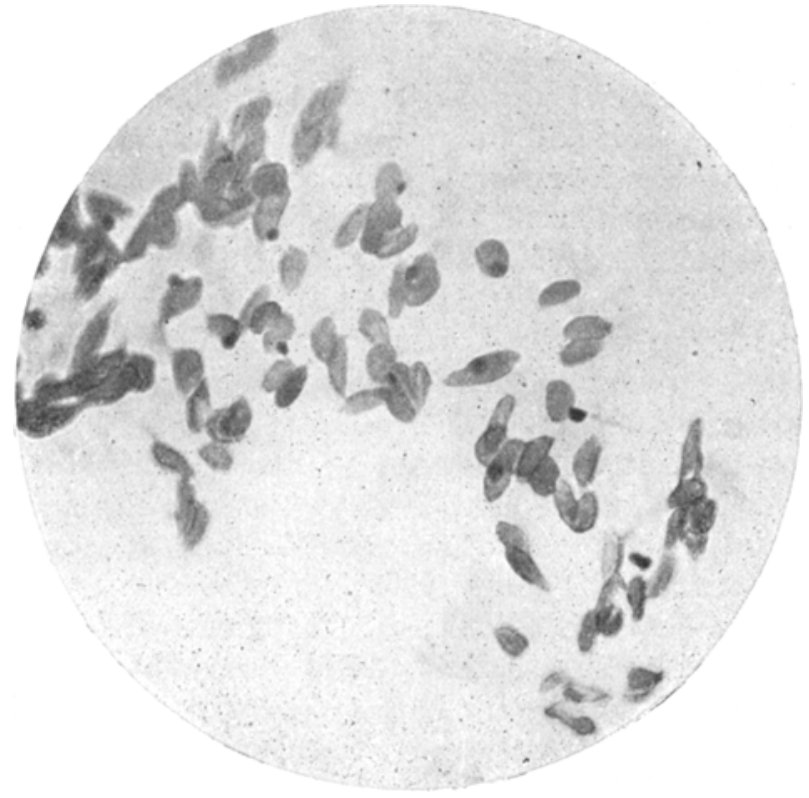

Abb. 3. Plättchenkernige Erythrocyten. Schnellfixation, Armvenenblut des Menschen, leichte Anämie. Mikrophotogramm eines fixierten Blutflöckchens in Giemsa-Färbung.

Je nach der Zahl der Plättchen besaßen mehr oder weniger Erythrocyten derartige Kernchen, die Plät t c henkerne benannt wurden. Die geringste Störung der nicht einfachen Technik, Verzögerungen von Bruchteilen einer Sekunde oder Beimischung von Spuren des Gewebssaftes zeigten sogleich den Austritt dieser Plättchenkerne, Beginn der Zusammenrottung und Zerfall in die bekannten zwei Schichten von hyaliner bläulicher Grundsubstanz und zentralen Purpurkörnchen. Die durch die sorgsamste Technik erzielte Kernchenform durfte also mit großer Wahrscheinlichkeit als die eigentlich wahrhafte Form angesehen werden, zumal sie nach Größe, Homogenität und Gestalt viel besser mit der Plättchengestalt im lebenden Gefäß übereinstimmte (Abb. 3). 
Als Stützen für die Kernauffassung des gesamten Plättchens führe ich aus der älteren Literatur an: Vorkommen der Blutplättchen allein im kernlosen Blut als drittes Formelement [Bizzozero ${ }^{2}$ ), zuletzt sehr überzeugend A ynaudi28)] Auftauchen der Plättchen vor den Leukocyten beim Embryo mit Auftreten des kernlosen Erythrocyten, [Enge ${ }^{20}$ ), Helber ${ }^{21}$ ) u.a.], chemisch Nucleingehalt (Lilienfeld und Scherer), Purinstoffe (Schittenhelm u. Bodong), Resistenz im Verdauungsversuch (Sacerdotti, Ke $m p$ und Calhoun); Hämatoxylinfärbbarkeit (Bizzozero, Howell, Deetjen, Kopsch), Methylgrünannahme (Kemp, Calhoun u Harris), Azurfärbbarkeit [Pappenheim, Argutinski]*).

Physiologisch ist die blitzschnelle Zersetzlichkeit der Blutplättchen seit Bizzozero'21) und damit das Sekundäre der gewöhnlichen körnigen Form anerkannt.

Diese Plättchenkerntheorie knüpit also direkt da an, wo die P a p p en h e im sche Lehre von der Entkernung histologisch auflört und hat das auffällige plötzliche Verschwinden der reifen gelösten Kerne im Mark geradezu zur Voraussetzung. Andererseits wurde das als außerordentlich leicht zerstörbar geschilderte Blutplättchen des peripheren Blutes durch neue besonders konservierende histologische Methoden von der körnigen Zerfallsform auf eine dunkelazurrote, pyknotische Kernform gebracht, die gerade bei diesen Methoden isoliert an oder in Erythrocyten liegt. Damit scheint mir eine durchaus gangbare Brücke geschlagen, die wenigstens einer Nachprüfung wert ist.

Statt dessen haben sich die neueren Untersucher der Blutplättchenfrage, beherrscht von der gewiß bestechenden Theorie Wright ${ }^{25}$ ), allgemein der Megakaryocyten-Entstehung der Blutplättchen, d. h. ihrer Bildung aus den schwach blauen, azurophil-gekörnten Protoplasmen der Riesenzellen des Knochenmarkes zugewandt.

Für diese Theorie werden angeführt: Gleichheit der Färbung, ähnliches Aussehen der Ausstrich-Blutplättchen und der protoplasmatischen Pseudopodien der Riesenzellen, angeblich auf die Säuger beschränktes Vorkommen dieser Zellart (?), Hineinragen der Riesenzellen in die Bluträume des Markes, das eine Abreißung der Plättchen leicht erklärbar machte, endlich klinisch-pathologische Übereinstimmung der Vermehrung und Verminderung mit den Blutplättchen.

Dagegen aber ist anzuführen: die m. E. sicher erwiesene Tatsache, daß Blutplättchen nur sehr spärlich frei im Gefäß kreisen [Löwit, Heintz, Eberth und Schimmelbusch, Laker, Arnold, Verfasser $\left.\mathrm{r}^{4}\right)$, viel feinkörnigeres Aussehen der Riesenzellprotoplasmen im Ausstrich, das sogar Anhänger der Wrightschen Theorie hervorheben [Naegeli $\left.{ }^{26}\right)$, Oelhafe $\left.\left.{ }^{27}\right)\right]$ und endlich Fehlen der kernartigen Färbung

*) Näheres s. Arbeit ü. d, E. ${ }^{4}$ ). 
und Struktur bei den Protoplasmateilchen gegenüber den gut konservierten Blutplättchen der neuen Schnellfixation.

Bis zur Widerlegung der beschriebenen Präparationen, die nirgends erfolgt ist*), kann ich mich der $\mathrm{Na}$ a geli schen ${ }^{2}$ ) Ansicht nicht anschließen, daß die Blutplättchenfrage restlos durch die Wrightsche Theorie geklärt ist, zumal mir erfahrene Histologen wie Ebner, Lubarsch, Hirschfeld das kernartige Aussehen und die kernartige Lage der „Plättchenkerne" so sehr zugaben, daß sie das normoblastoide Aussehen der Plättchenkernigen hervorhoben und die Verwechslung mit Normoblasten für möglich hielten, bis der Vorgang der Fixierung, die Úbergänge zum bekannten Bilde des Plättchens und das Fehlen von Normoblasten im gleichzeitigen Ausstrichpräparat diese Fehlerquelle sicher ausschlossen.

An dem Objekt der Blutplättchen zeigt sich die ganze Schwierigkeit einer klinisch richtigen Beurteilung von morphologischen Blutelementen, deren Natur histologisch nicht feststeht. Der Versuch aus den klinischen Befunden des Blutplättchens auf seine Genese zu schließen, muß nach den bisher vorliegenden Arbeiten als im vollen Umfange gescheitert angesehen werden, da jede Plättchentheorie ganz glaubhafte Tatsachen aus der großen Masse des Materiales heraushob, ohne die kleinen oder großen Gegenbefunde zu beachten. So haben z. B. zuletzt Decastello und Meissner ${ }^{29}$ ) auf anscheinenden Parallelismus zwischen der Gesamtheit der Leukocyten und den Blutplättchenzahlen hingewiesen, allerdings ohne den durchgreifenden Schluß, daß die Plättchen nun auch wirklich von Leukocyten stammen müßten, aber mit einem deutlichen Hinweis auf die Megakaryocyten. Dabei zeigen viele Hyperleukocytosen und Leukopenien, auch Leukämien ein ganz entgegengesetztes Verhalten der Gesamtleukocyten, wie Port, Akyama, Helber u. a., sowie die folgenden eigenen Untersuchungen erweisen. Auch Wright und seine Anhänger haben klinische Ubereinstimmungen zwischen Riesenzellverhältnissen und Blutplättchenzahlen angeführt [Bunting ${ }^{30}$ ), Dukt $\epsilon^{31}$ ), Frank ${ }^{32}$ ), Glanzmann ${ }^{33}$ ) u. a.].

Fußend auf der Wrightschen Theorie stellte Frank den Begriff der splenogenen Myelotoxikosen auf, indem er die Leukopenie der Krankheiten mit Milztumoren in Verbindung brachte mit der häufig verminderten Blutplättchenzahl dieser Fälle. Die Riesenzellen

*) Auch durch die inzwischen erschienene kritische Studie Briegers, Deutsch. med. Wochenschr. 38, 1920, der objektiv alle morphologischen Bilder bestätigt, sie aber als Anklebung deutet, ist natürlich eine Widerlegung nicht erfolgt (s. m. Antwort 1. c. 46). Die Beweisführung von Degkwitz, Deutsch. med. Wochenschr. 1, 1920, ist morphologisch nicht stichhaltig (s. m. Antwort l. c. 7). 
sollten als das empfindlichste Element des Markes in erster Linie geschädigt sein. Er erwartete demgemäß pathologisch-anatomisch bei dem hierher gerechneten hämorrhagischen Typhus und bei dẹ Purpura starke Verminderungen dieser Zellart. Kaznelson ${ }^{34}$ ) aber wies ganz richtig auf die bekannten Befunde starker Vermehrung und Ausschwemmung der Riesenzellen bei Typhus hin, die Aschoff, Lubarsch u.a. gefunden hatten. Er selbst fand in einem Falle von schwerer hämorrhagischer Diathese mit Verminderung der Blutplättchen auf 2-600 im cmm starke Phagocytose der Plättchen im retikuloendothelialen Apparat [wie Bernhardtas)] und starke Vermehrung der Riesenzellen in der Milz. Nach der sehr günstig wirkenden Splenektomie stiegen die Plättchen so schnell in 3 Tàgen auf 246000 , daß nur die früher von ihm aufgestellte Theorie der Thrombocytolyse annehmbar blieb: die Blutplättchen waren zwar in diesem Falle reichlich gebildet, aber durch eine schädliche Einwirkung der Milz vernichtet oder gelöst worden; mit dem Fortfall der Schädigung trat die eigentliche Zahl der Plättchen entsprechend den reichlichen Riesenzellen in Erscheinung. Ich halte sowohl Franks splenogene Leukopenie wie Kaznelsons Thrombocytolyse für sehr fruchtbare Arbeitshypothesen, muß ihnen aber mangels wirklicher histologischer Unterlagen für die gesetzmäßige Übereinstimmung mit den Megakaryocytenbefunden eine bindende Beweiskraft für die Wright tsche Theorie vorläufig absprechen.

Wenn ich nun in folgenden eigenen Untersuchungen die klinische Übereinstimmung der Blutplättchenbefunde mit anämischen Veränderungen aufzeige, werde ich mich doch hüten, diese nunmehr für einen bindenden Beweis meiner Plättchenkerntheorie anzusehen, der nur histologisch geführt werden kann. Aber nachgewiesen werden soll, daß tatsächlich $\mathrm{m}$. W. kein klinischer Befund irgendwie gegen diese Ansicht spricht.*)

Zunächst habe ich in Fortsetzung meiner früheren Arbeiten über den Erythrocyten. V: Über Blutplättchen und über Kernreste der kernlosen Erythrocyten (Fol. haem. Archiv 14, 155, 1912) und über „Die Lösung der Blutplättehenfrage “ (Dtsch. med. Wochenschr. Nr. 49, 1918) das histologische Verhalten der Blutplättchen bei möglichst verschiedenem Material geprüft.

Studiert man mit der höchst einfachen Technik Fonios ${ }^{37}$ ) für Zählung der Blutplättchen (Auffangen in 14\% Magnesiumsulfat durch Aufbringen eines Tropfens auf die Haut und Stich durch den Tropfen, Trocknung, Fixierung, intensive Giemsa-Färbung) viele Präparate, so fällt sehr bald ein durchaus verschiedenes Verhalten und

*) Degkwitz hat. Fol. haematol. 25, 3, 1920 das Gegenteil ohne Beweise behauptet. 
Aussehen der Plättchen auf. Die Erhaltung der Plättchen ist allgemein viel besser als im Ausstrich und die Grundform ist die eines kleinen ausgelaugten, azurophilen Bläschens mit scharfem Kontur und höchstens einigen blassen feinen anhängenden Fäserchen. Sie nähert sich also dem Aussehen meiner Schnellfixationen im gewissen Grade. Vereinzelt sieht man selbst ganz kernartige, auch strukturierte Plättchen. (Vgl. die Text-Abb. 3 und 13 mit Taf. III, a,d u. e.) Gewisse Fälle zeigen nun auf den ersten Blick eine durchgehends viel dunklere Färbung der Plättchen, gleichmäßigere Größe, runderes, kernähnlicheres Aussehen und gerade diese Fälle pflegen auffallend zahlreich bis zu sehr erheblichen Prozentsätzen diese Plättchen wie Kerne in bzw. a uf den Erythrocyten aufzuweisen, so daß ganz das Bild „plättchenkerniger Erythroeyten" meiner Beschreibung vorliegt.

Der Einwand daß es sich hier um mathematische Zufälligkeite $n$ handelte, insofern als bei vermehrter Zahl notwendig auch mehr Blutplättchen auf Erythrocyten liegen müßten, ist leicht abzuweisen, da gerade die sehr starken Blutplättchenvermehrungen oft lange vergeblich solche Kernlagen suchen lassen. Die kleine Tabelle der höchsten Prozentzahlen „Plättchenkerniger“ meines Materiales zeigt einleuchtend die Unabhängigkeit von den Erythrocyten- und Blutplättchenverhältniszahlen:

\begin{tabular}{cccl} 
Plättchenkerne & Blutpl.: Erythroc. & Blutpl. absolut & \multicolumn{1}{c}{ Art des Falles } \\
$35 \%$ & $82: 1000$ & 389500 & Endokarditis; Dyspnöe. \\
$20 \%$ & $171: 1000$ & 837900 & Mediastinaltumor; Dyspnöe. \\
$14 \%$ & $112: 1000$ & 420000 & An. perniciosa? Remission? \\
$11 \%$ & $108: 1000$ & 403000 & Malaria-Rekonvaleszenz \\
$10 \%$ & $88: 1000$ & 456000 & Tbc. pulm. Dyspnöe. \\
$6,5 \%$ & $192: 1000$ & 912000 & Abdominaltumor. \\
$6,5 \%$ & $121: 1000$ & 677000 & Dyspnöe; Pneumothorax; Tbc. \\
$6,5 \%$ & $62: 1000$ & 197000 & Dyspnöe; Tbc. III schwer. \\
$3 \%$ & $142: 1000$ & 695000 & Icterus luet. Hämolyse. \\
$2,5 \%$ & $120: 1000$ & 570000 & Hämorrhoiden-Anämie.
\end{tabular}

In einer Reihe dieser Fälle habe ich meine Schnellfixation mit besonderem Erfolg angewendet und damit meine früheren Angaben bestätigt, daß gewisse anämische Zustände ein leichteres Haften der Blutplättchen an Erythrocyten bzw. eine verminderte Ablösbarkeit, eine größere Kernähnlichkeit und damit ein anscheinend dem Nor moblasten näherstehendes Stadiu m junger Erythrocyten im Sinne meiner Theorie zeigten.

Die folgenden ausführlichen Tabellen enthalten in der Rubrik: histologisches Verhalten der Blutplättchen entweder die Prozent-Zahlen der Plättchenkernigen oder durch $\mathbf{K}+, \mathbf{K}++$ einen Hinweis auf auffallendes oder starkes Hervortreten derartiger Kernhaltiger. Sie ähneln 
durchaus den von Preisich und Heim ${ }^{18}$ ) im Knochenmark als Vorstufen angenommenen abgeblaßten Kernen von Normoblasten. Einige Fälle zeigten auch derartige Formen im Trockenausstrich neben sehr deutlich kernartigen freien Plättchen, hatten aber kaum echte Normo. blasten, die jeder Hämatologe sofort durch ihre viel derbere Kernstruktur von den Plättchenkernigen trennen würde.

$\mathrm{Nur}$ diese hoffreien, mosaikartig de $\mathrm{m} \mathrm{Hb}$-Teil eingesetzten Plättchenkerne werte ich als wirklich noch einliegende Kernchen, nicht aber die in der Regel abgebildeten gehöften und körnig zerfallenen Plättchen der Autoren (Engel, Grawitz, Helber, Preisich u. Heim, Brockbank u. a.), da ich letztere als beweislose Zufälligkeiten betrachte.

Bei aufmerksamen Suchen gelingt es fast in allen Fällen, sauberste und schonendste Technik vorausgesetzt, mindestens einzelne Plätt. chenkernige auch im Ausstrich aufzufinden. Unterstützend für ihre Beweiskraft wirkt der recht auffällige abweichende $\mathrm{Hämo-}$ globinton dieser Erythrocyten, den man schwer beschreiben kann, der aber auch Anfängern sehr oft sofort auffällt. Er kann als ein jüngeres Stadium des Hämoglobins gedeutet werden (mit einem Anflug von Polychromasie?) und erinnert sehr an den oft ebenso auffallenden $\mathrm{Hb}$-Farbton orthochromatischer Erythroblasten.

Noch bemerkenswerter sind die auch in Fonio-Präparaten bereits aufzufindenden vereinzelten durchaus dunkelpyknotischen Blutplättchen, die in meinen Schnellpräparationen bei gutem Gelingen fast ausschließlich zu sehen sind. Sie bezeichnen meiner Theorie nach die direkte Anknüpfung an den pyknotischen, verkleinerten und leicht enucleierbar gewordenen Vorstufenkern, nur ist das Magnesiumsulfatverfahren eben nicht geeignet, der Enucleation vorzubeugen, weil es nicht fixiert. Darum gelang auch meines Erachtens Aynaud ${ }^{28}$ ) bei seinem Pipettierverfahren mit ähnlichen gerinnungshemmenden Lösungen trotz guter Erhaltung der Blutplättchen kein Nachweis des Zusammenhanges mit Erythrocyten. Taf. III, d gibt eine Übersicht der vorkommenden Blutplättckenformen im Foniopräparat bei einem vielleicht durch ein Magenulcus etwas anämischen, dem Zahlbefunde und Blutbild nach aber sonst normalen Menschen; bei ganz Gesunden sind die Blutplättchen allerdings durchgehends sehr farblos und uncharakteristisch. Endlich gibt Taf. III, e stark pathologische Riesenblutplättchen einer myeloischen Leukümie, die im gleichzeitigen Ausstrich merkwürdigerweise fast farblos bläulich mit einem scharf begrenzten helleren runden Innenkörper ersehienen. Im Tierblut z. B. Kaninchen, finden sich schon normal Formen, die ganz den pathologischen des menschlichen Blutes an Kernähnlichkeit gleichen, wie ja das Blut 
kleiner Versuctsticre an sich schon dem anämischen Blutbilde des Menschen näher steht.

Derartige Riesenplättchen haben in letzter Zeit besonders Fonic ${ }^{38}$ ), Glanzmanris ${ }^{33}$, R.Schmidt ${ }^{39}$ ), Kaznelson ${ }^{34}$ ) beschrieben und sie als Beweise pathologischer Entartung der Plättchen bei der Purpura angeführt.

Charakteristisch beschreibt Glanzmann, ein entschiedener Anhänger der Wrightschen Riesenzellentheorie, ihr Aussehen: „Die einzelnen Granula verschmelzen ineinander zu einem kompakten meist sehr intensiv-dunkelviolett-schwarz gefärbten Gebilde, welches man am besten mit einem pyknotischen Erythroblastenkern vergleichen kann"c (1. c. 1918. 116).

Fonio weist richtig darauf hin, daß auch bei sekundären Anämien schon derartige pyknotische Plättchen vorkommen und ibre Spezifität daher für Purpura bzw. Thrombasthenie nicht stimme. Die von den übrigen Autoren vertretene degenerative Auffassung des dunklen Plättchen ändert R. Schmid $t^{39}$ ) in eine regenerative Bedeutung um, weil er wie Kaznelson unmittelbar nach dem Entfernen der schädigenden Milz ein enormes Emporschnellen der Plättchenzahlen bemerkte, mithin eine unterdrückte Mehrbildung bereits bestanden haben müßte.

Meiner Theorie nach bedeuten die Riesenplättchen einfach die besonders früh enucleierten Erythroblastenkerne, da auch ich mit Kaznelson eine verstärkte Thrombocytolyse, d. h. hier eine sinngemäß beschleunigte Chromatinolyse und Entkernung der Vorstufen annehme, wie das ganz eigenartige Verhalten der Purpuragruppe es theoretisch erfordert.

Versuchen wir nun klinisch das besonders zahlreiche Auftreten von Plättchenkernigen und kernartigen freien Plättchen zu werten, so scheint neben einer gewissen Anämisierung eine erhöhte Anforderung an den Erythrocytenapparat durch Dyspnöe oft vorzuliegen. Da die Vermehrung der Blutmenge wie der Erythrocytenzahlen bei dyspnoischen Zuständen bekannt und einleuchtend ist, würde sich dies im Sinne der Kernchentheorie ganz ausgezeichnet mit einer gesteigerten Einf uhr frischgebildeter und jüngerer Elemente, gesteigerter Erythropoese, decken. Dazu paßt der gleiche Befund gesteigerter Erythropoese bei Hämolysen, Malaria, Tumoranämien. Dagegen ließen el:enso einleuchtend die perniziösen Anämien mit ihren mannigfachen pathologischen Karyolysen und karyorrhektischen Prozessen (multiple Kernkugeln, azurophile Polychromasie), die akuten Infektionen (Hemmung der Erythropoese) und die Purpura-Fälle (erhöhte Zerstörung) bei direkt verminderten Blutplättchenzahlen die wirklichen Kernartigen sehr zurück. 1reten. 
Auch bezüglich der berichteten schnellen Vermehrung der Blutplättchen nach Milzexstirpation sind parallele histologische Veränderungen der Erythrocyten bekannt, die für eine außerordentlich lebhaft einsetzende Erythropoese sprechen. Besonderes Interesse verdienen auch hier wieder die lange andauernden Vermehrungen von Kernkugeln [Schur ${ }^{9}$ ), Roth'11), Hirschfeld und Weinert ${ }^{13}$ ), Karlbaum $\left.{ }^{15}\right)$ ]. Da Hirschfeld ${ }^{12}$ ) recht wahrscheinlich die Ursache in dem Fortfall von Hormonen sieht, die vorher die Anämisierung und den Entkernungsprozeß im Knochenmark unterbielten, liegt a uch hier ein charakteristischer Zusammenhang der Blutplättchenfrage mit dem Entkernungsprozeß zutage, zu dem die Kerntheorie sehrgut paßt.

Histologisch ist die Milz als Ort der Erythrocytenzerstörung wie der Plättchenansammlung und -Vernichtung bekannt, ein Parallelismus, der von Kaznelson gerade bezüglich der Phagocytose beider, der Erythrocyten und der Plättchen, im retikulo-endothelialen Apparat noch besonders betont wurde. Klinisch dürfte daher die wesentliche endokrine oder hormonale Mitwirkung der Milz bei anämischen erythrocytären Vorgängen mehr oder ebenso plausibel sein wie die bestechende Franksche splenogene Leukomyelotoxikose.

Klinisch dürften wir also im Sinne der Kernchentheorie a us dem Auftreten der resistenteren, besser haftenden und den Vorstufen näherstehenden Blutplättchen den gleichen Schluß etwa wie aus dem Auftreten von Polychromatischen ziehen, d. h.an eine Regeneration der Erythrocyten denken. Gleichmäßiges, blasses Aussehen der Plättchen spricht für normale Entkernung, normale Erythropoese. Starke Anisocytose und färberische Ungleichheit deuten a uf Störungen und Ungleichheiten des Ersatzes.

Für die Verwertung der Blutplättchenzahlen ist nun von einschneidender Bedeutung, daß nach der vorgetragenen Theorie jedes Plättchen im Prinzip bei leidlich physiologischer Entkernung auch einem jungen Erythrocyten entspricht, während die frühere "Granatentheorie" eine sichere Beziehung schwer machte. Mögen auch recht polymorphkernige Erythroblasten vorkommen [siehe besonders $\left.\mathrm{Hammerschlag}{ }^{40}\right)$ ], so sind doch wirkliche Kernzertrümmerungen, die mehrere Blutplättchen aus einer Zelle stammen ließen, bei normalen und physiologisch gesteigerten Erythropoesen kaum zu finden. Dagegen wären z. B. die kleinen Plättchensplitterformen der perniziösen Blutbilder ein gleiches Hindernis für korrekte Zählung wie die Schistocyten, heben aber wohl ebensowenig wie diese die klinische Anwendbarkeit auf.

Für das Studium dieser Verhältnisse schienen mir vor allem Kurven- 
untersuchungen nach starken experimentellen und pathologischen Anämien auf Grund der hübschen Arbeit Richardson s $^{41}$ ) der gegebene Weg, obgleich ihre Mühsamkeit ihre Anwendung beschränkt. Richardson hatte durch starke Blutentziehungen am Kaninchen sehr auffallende Vermebrungen der Blutplättchen erzeugt, die auf der Höhe der Entwicklung Blutplättchen und Erythrocytenzahlen

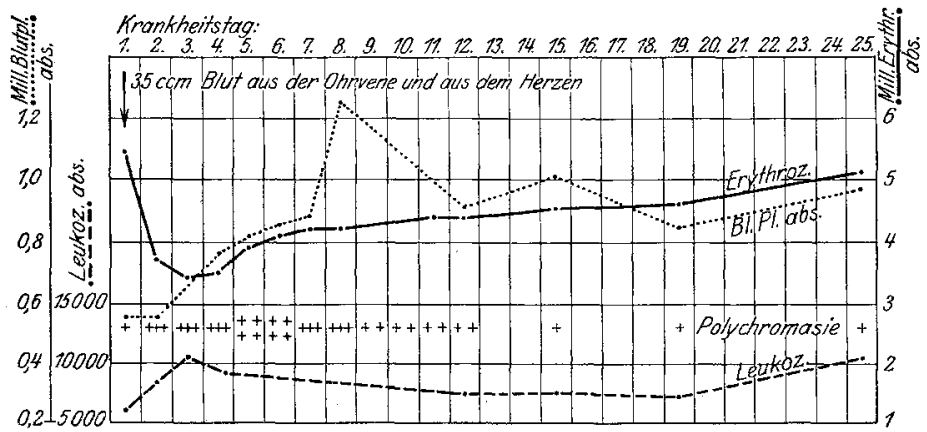

Abb. 4, Kurve $1 \mathrm{a}$ *). Blutplättchen absolut mit zunehmender Regeneration vermischt. Leukocyten wenig yerändert.

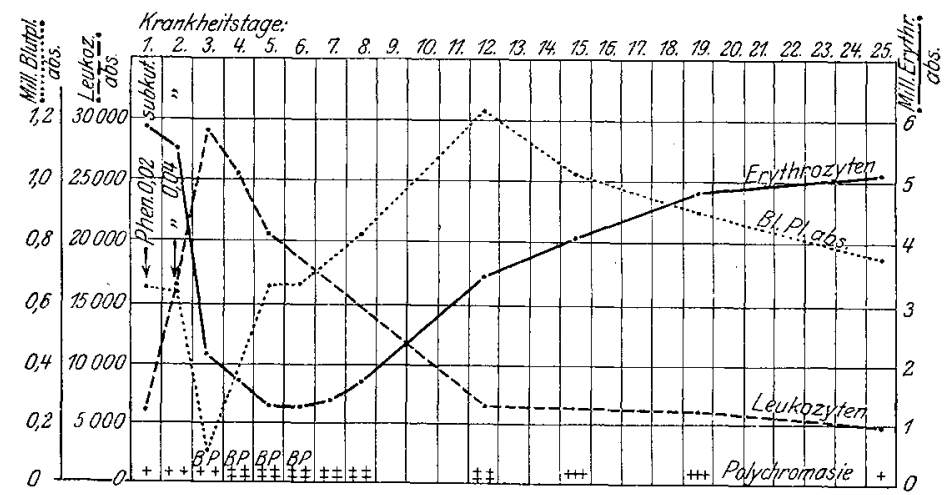

Abb. 5, Kurve II a. Erhöhung der absoluten BIutplättchenzahlen mit der stärksten E-Regeneration. Leukocyten enitgegengesetzt.

sehr nahe zusammenführten. Er zog daraus genau wie Boellke, Preisich und Heim, Helber, Brockbank aus ihrem klinischen Material den Schluß, daß die Blutplättchenbild ung in direkter Beziehung zur Erythropoese oder zur Regeneration der Anämie stehen könnte.

Auf Grund von Vorversuchen, die in meiner ausführlichen älteren Arbeit ${ }^{4}$ ) beschrieben sind, anämisierte ich ein Kaninchen durch Ent-

*) Auf allen Kurven sind die Blutelemente durch die gleichen Linien bebezeichnet. 
ziehung von $35 \mathrm{ccm}$ Blut aus dem Herzen (Punktion), ein zweites durch subcutane Einspritzung von Phenylhydrazin, hydrochlor, 4 proz. wäßrige Lösung, 0,02 $\mathrm{g}$ am ersten, $0,04 \mathrm{~g}$ am zweiten Tage (siehe die Kurven Ia und IIa, Abb. 4 u. 5). Beide Kurven lassen einen schnellen Absturz der Erythrocyten und ein gleichmäßiges Wiederansteigen erkennen, das wie bekannt bei der Vergiftungsanämie wohl infolge der im Körper gebliebenen Baustoffe viel schneller erfolgt. Die Leukocytenwerte ver-

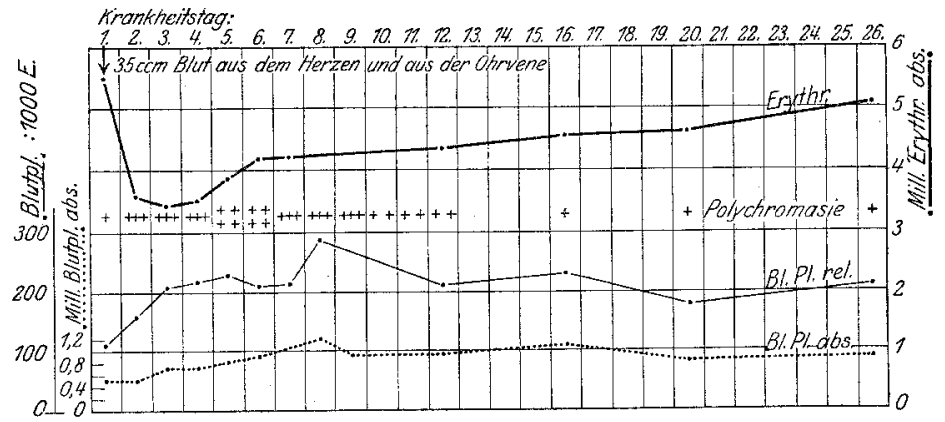

Abb. 6, Kurve 1b. Blutplättchen sind während der starken E-Regeneration absolut und mehr noch relativ vermehrt.

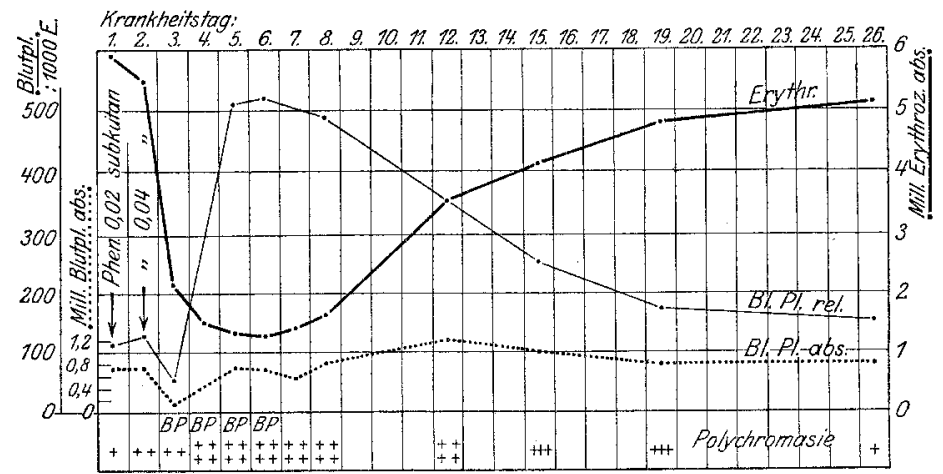

Ab3. 7, Kurve II b. Blutplättehen sind während der stärksten Regeneration sehr stark relativ, aber auch arsteigend absolut vermehrt. Annäherung der absoluten E. und Blutplättchenwerte.

ändern sich nur bei der Vergiftung in schnellem An- und Abstieg. Die absoluten Blutplättchenwerte steigen nach Blutentziehung sofort, 'nach der Vergiftung erst nach jähem Absturz rapide an. Sie erreichen während der ganzen Regenerationsperiode deutlich erhöhte absolute Werte, die bei der langsamer ausheilenden Blutverlustanämie auch länger andauern. Viel auffälliger werden jedoch die Befunde noch, wenn man entsprechend der Plättchenkerntheorie folgerichtig das relative Verhältnis der Blutplättehen zu den Erythrocyten 
beachtet, das allerdings nicht als mathematischer Beweis brauchbar ist, weil es das zu Beweisende in die Voraussetzung nimmt (Kurve Ib und II b, Abb. 6 und 7).

Mit der mächtig einsetzenden Regeneration schnellen z. B. bei der Vergiftung die „Kernchen“ der Erythrocyten auf das Mehrfache des Normalen und nähern sich, wie die absolute Kurve II b beweist, sehr erheblich den absoluten E.-Zahlen, am 5. bis 8. Tage hier etwa bis zur Hälfte. (In einem früheren Versuch erreichte ich beinahe das Verhältnis $1: 1$ und dem entsprach durchaus das Schnellfixationsbild, das nun fast alle Erythrocyten wie Kernhaltige zeigte. Eine erst im Schwarzdruck veröffentlichte Abbildung dieses Präparates ist Taf. III a. Die relativen Zahlen blieben sehr plausibel noch erhöht, wenn die absoluten Blutplättchenwerte bereits die normale Höhe wieder erreicht haben, entsprechend der immer noch latent weiter wirkenden Regeneration. Die Blutungsanämie gibt in gemäßigter Form. genau das gleiche (Kurve $I b$ ).

Am Menschen ist ähnlich geeignetes Material auf der inneren Klinik seltener, doch fand ich einen günstigen Fall von einer abundanten Magenblutung bei multiplem Magengeschwür (Kurve III, Abb. 8). Wahrscheinlich bestand bereits vor der Aufnahme Anämie, doch trat nach den Aussagen der Patientin die

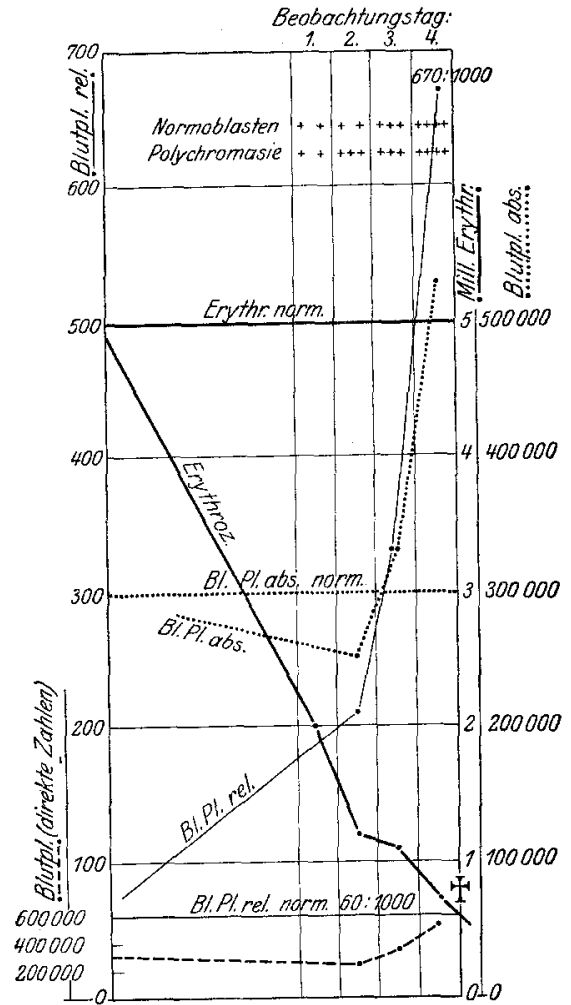

Abb. 8, Kurve III. Sehr starker, relativer und erheblicher, absoluter Anstieg der Blutplättchen mit der stärksten Erythroregeneration, die zahlenmäßig durch neue Blntungen mit E-Verlust überholt wurde. erste schwere Blutung am Aufnahmetage in der Poliklinik ein und wiederholte sich unter der Beobachtung. Während der 4 Tage bis zum Tode durch die zweite Blutung stieg die Blutplättchenzahl von dem ziemlich normalen Verhältnis $60: 1000$ auf $670: 1000, d$. h. relativ auf das Zehnfache und absolut auf fast das Doppelte, zugleich mit dem massenhaften Auftreten von Normoblasten und Polychromasie. 
Wegen der leichten Kontrolle der Infektion durch den Parasitennachweis und wegen der starken Anämisierung habe ich weiter MaIariaf.̈̈lle in dieser Form untersucht (Kurve IV und Kurve V, Abb. 9 und 10). Hier zeigte sich im Anfang während der unbekämpften Infektion die bekannte Herabsetzung der absoluten Plättchenzahl auch relativ entsprechend einer deutlichen Hemmung und Schädigung der Regeneration (Polychromasie nur spärlich) und der fortschreitenden Anämisierung. Mit der Chininsalvarsankur und dem Schwinden der Parasiten stiegen mit gleichzeitig zunehmender Polychromasie die Blutplättchenwerte

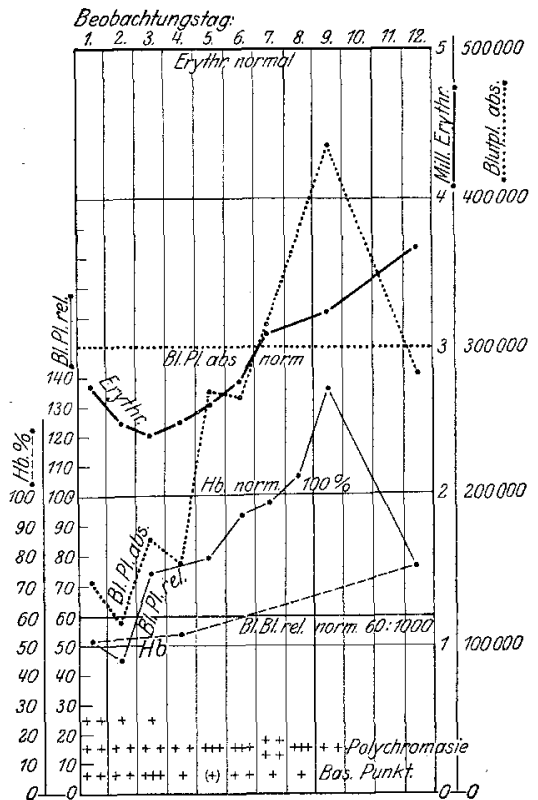

Abb. 9, Kurve IV. Relativer und absoluter Anstieg der Blutplättchen mit der Erythroregeneration.

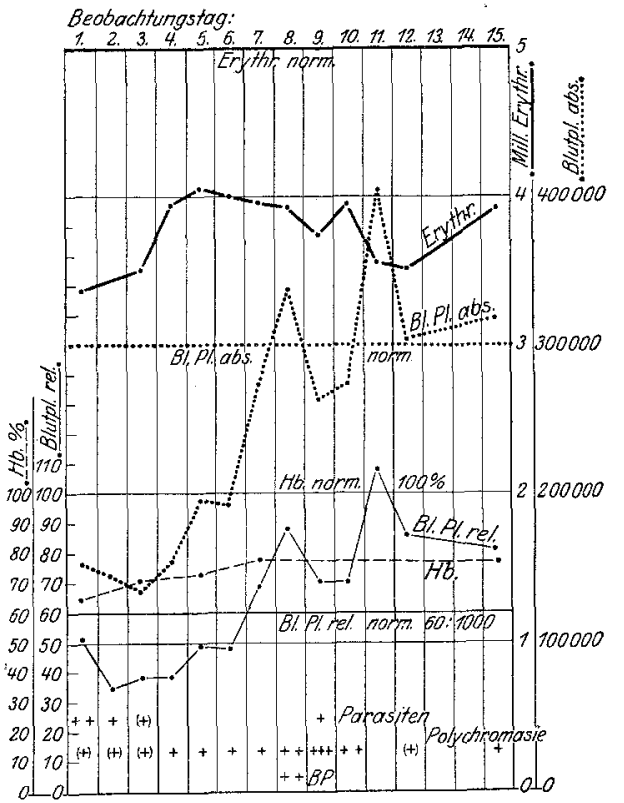

Abb. 10, Kurve V. Relatives und absolutes Ansteigen der Blutplättchen mit der Erythroregeneration. Einschnitt durch Parasiten am 9. Tage.

relativ und absolut auf übernormal. Im Falle Benkel (Kurve IV) vermehrten sich die F. korrespondierend und mit dem Nachlassen der Regeneration sanken wie bei den Kaninchen auch die relativen Blutplättchenwerte ab. Im Falle Skuras (Kurve V) blieben jedoch trotz rapiden Anstieges der Plättchen und lebhafter Polychromasie die absoluten E.-Werte unerklärlich stehen, bis am 9. Beobachtungstage das Wiederauftreten der Parasiten eine gewisse Behandlungsresistenz und eine latent fortglimmende Infektion erwies, gegen die die Erythropoese nicht ankam. Mit den Parasiten bildete sich ein deutlicher Sattel in der Blutplättchenkurve (vorübergehende Hem mung), die aber 
nach verstärkter Therapie einem erneuten Anstieg Platz machte. Mit der langsameren Regeneration sanken dann auch die Plättchen.

Bei einer An a mia perniciosa. Bier mer sehr typischer Art ergab die Kurve VI, Abb. 11 eine mächtige Steigerung der niedrigen Blutplättchenzahl mit Beginn der Arsentherapie, die zu den besten Hoffnungen berechtigte, ebenso wie die starke polychrome Regeneration. Klinisch blieb jedoch der Zustand bei fortbestehendem Blutzerfall mit Ödem, Ikterus und Fieber mäßig. Die E.-Zahl fiel sogar, weil a ugenschein lich die Blutzerstörung noch die Regeneration überwog. Dann trat klinisch eine so erhebliche Verschlechterung ein, daß die Angehörigen gewarnt werden mußten (auffallende Blässe, stärkere Zungenbläschen, nervöse Stimmung mit Parästhesien, Subikterus). Während dieser Zeit sanken die Blutplättchen auch relativ wieder auf unternormal

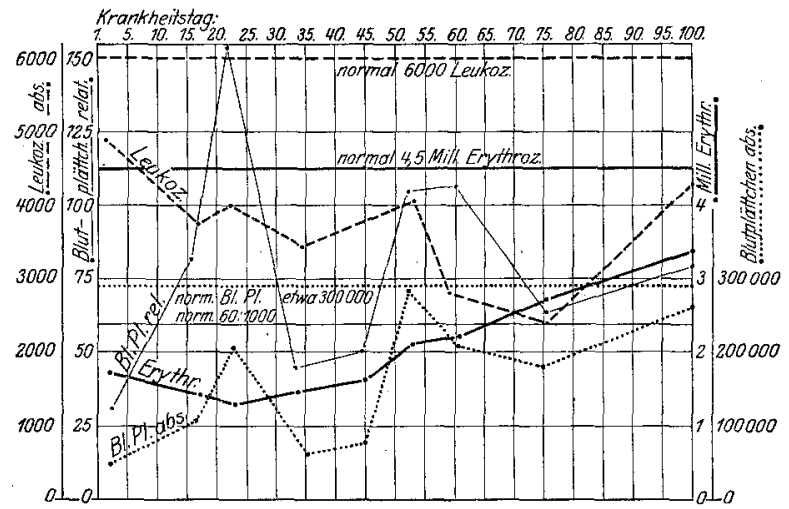

Abb. 11, Kurve VI. Frau D. Anämia perniciosa. Blutplättchen absolut unter normal; relativ nur im Tiefstande bei der Aufnahme und bei einem Rückfall unter normal. Starke absolute und relative Vermehrungen der Bl. Pl. im Anfange der im Blutbilde auftretenden E-Regenerationen.

mit starker Anisocytose. Mit Besserung dieser Symptome begann die sehnlich erwartete Remission unter stürmischem Anstieg der Plättchen. relativ und absolut; die E.-Werte stiegen nun stetig, auch die Plättchen gleichmäßiger, bis fast normale Befunde bei bald vollkommenem Wohlbefinden erzielt wurden (Therapie : kombinierte Arsen-Tierkohlebehandlung mit Magen- und Darmspülungen, zuletzt wöchentliche intramuskuläre Blutinjektionen). Die Blutplättchen waren jetzt kaum noch von normalen nach Färbung und Größe zu unterscheiden.

Die Kurven aller dieser experimentellen und klinischen Fälle erlauben also eine ganz zwanglose und einleuchtende Anwendung der Plättchenkerntheorie: immer entspricht die höchst relative und meist a uch absolute Zahlder Plättchensehrgutden zuerwartenden Einschwemmungen junger Erythrocyten mit noch anhän. 
genden Kernchen, eine Auffassung, die auch durch das sonstige histologische Bild der Erythrocyten und das kernartigere Aussehen der Plättchen gut gedeckt wird.

\section{Blutplättchenzahlen in der Klinik.}

Die folgenden Tabellen geben eine Utbersicht über eigene Zäblungen der Blutplättchen in den sich bietenden klinischen Fällen der Inneren Klinik. Ich will gleich vorausschicken, daß sie im wesentlichen die neueren Angaben der Literatur seit Hayem nur bestätigen Irgendwie erbebliche Abweichungen von den Zusammenstellungen, die ich in meiner älteren Arbeit ${ }^{4}$ ) S. 162 gab, hat sich bis auf die schon von vielen Seiten teilweise beanstandeten Ergebnisse Deter manns nicht gefunden.

Da viele dieser Arbeiten jedoch nur die absoluten Werte angeben und oft keine Beschreibung des sonstigen Blutbefundes enthalten, habe ich meinen Tabellen auch die Leukocytenzahl, das Leukocytendifferentialbild mit einem Stichwort, die Kernverschiebung als Index (Verhältnis der unsegmentierten zu den segmentierten Neutrophilen) die Erytbrocytenzahl, das relative Verhältnis der Plättchen zu den Erythrocyten, das Auftreten Polychromer und Basophil-Punktierter miteingetragen, um einen gewissen Einblick in den gesamten Blutbefund zu ermöglichen. Für die Leukocyten ist meine Differentialleukocyten-Einteilung mit Einbeziehung der Kernverschiebung [Verfasser ${ }^{42}$ )] zugrunde gelegt. Wo nicht andere Werte angegeben sind, bestand ungefähr das normale Verhältnis : $0-1 \%$ Basophile, 2-4\% Eosinophile, $0 \%$ neutrophile Myelocyten, $0 \%$ neutrophile Jugendliche, $3-5 \%$ neutrophile Stabkernige, $60-67 \%$ neutrophile Segmentkernige, $20-25 \%$ Lymphocyten, $6-8 \%$ Monocyten. Bei deutlicher Vermehrung einer Zellart ist vermerkt: Eos. = Eosinophilie; N. = Neutrophilie; Ly. = Lymphocytose; Mon. = Monocytose. Der Index der Kernverschiebung ergibt sich aus dem Verhältnis neutrophile Myelocyten + Jugendliche + Stabkernige: neutrophilen Segmentkernigen. Normal ist dieses etwa $1: 15$. Niedrigere Werte bedeuten Rechtsverschiebung z. B. $1: 20$, I : 30 usw., bis zum Fehlen der Unsegmentierten 0:62 u. a. (An. pernic.). Höhere Werte entsprechen den Linksverschiebungen z. B. $1: 8,1: 4$ usw. bis zur Umkehrung $2: 1$ usw.

Tabelle I: Absolute Vermehrungen der Blutplättchen (s. Seite 594) ist geordnet nach dem relativen Verhältnis Blutplättchen zu Erythroeyten entsprechend der Kernchentheorie. Einigermaßen entsprechen dieser Reihenfolge auch die absoluten Blutplättchenzahlen, was nach den obigen Kurven kein Zufall sein dürfte, obgleich es nicht viel beweist, da die Zablen direkt voneinander abhängig sind. Weniger zufällig erscheint aber sicher eine im allgemeinen entgegengesetzt steigende 
Erythrocytenzahl, wenigstens finden sich die niedrigsten E.-Werte fast ausschließlich im oberen Teil der Tabelle neben den höchsten relativen und absoluten Blutplättchenzahlen. Auch die starken Polychromasie- und Basophiliebefunde (Pl. = Polychromasie, B. P. = Basophile Punktierung) entsprechen gern den hohen Blutplättchenwerten. Einige besondere Einordnungen von Bl. Pl.-Befunden wie im Fall 14 (Sepsis), 21 (Malaria), 29 (Malaria), 34 (Tbc. pulmon.), 38 (Endocarditis ulcerosa) entsprechen infektiösen Zuständen zur Zeit leichterer Art, meist mit Milztumor, bei denen ein e periphere Ein wir $\mathrm{k}$ ung a uf die Plättchen mit Zablherabdrückung nicht unwahrscheinlich ist. Fall 29,34 und 38 zeigen auch eine a uffällige kernartige Struktur der Plättchen, die auf besondere Verhältnisse bei der Plättchenbildung deutet.

Die Leukocytenbefunde zeigen jede Spielart ohne erweislichen Zusammenhang mit den Plättchen.

Ätiologisch ergeben die Vermehrungen:

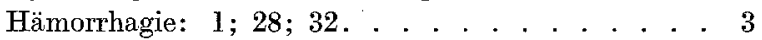

Hämolyt. Anämie: $2 ; 4 ; 17$. . . . . . . 3

Anämisierende Blutkrankheit: $18 ; 19 ; 26$. . . 3

Malaria: $21 ; 29$. . . . . . . . . . . . . . . . 2

Sepsis: $3 ; 7 ; 12 ; 14 ; 15 ; 16 ; 22 ; 24 ; 25 ; 33 . .10$

Dyspnöe: $8 ; 10 ; 13 ; 27 ; 34 ; 35 ; 38$. . . . . . 7

Tumor: $5 ; 6 ; 9 ; 11 ; 20 ; 23 ; 30 ; 31 . . . \quad . .8$

Würmer: $36 ; 37 . . . . . . . . . .2$

38 Fälle.

Daraus ergibt sich ohne $Z$ weifel, daß absolute Blutplättchenvermehrungen mit anämisierenden Krankheiten einhergehen, wobei die Blutplättchen im allgemeinen mit de $m$ Grade der Regenerations prozesse*) steigen, die wieder u mo stärkersind, jeniedriger die Ery throcytenzahl bei erhaltener Regenerationsfähigkeit des Knochen markes gesunken war.

Eine besondere Beachtung verdienen hier die dyspnoischen Fälle, da sie auf die bekannte Vermehrung der Blutmenge und der E.-Zahl bei erhöhten Anforderungen an die Atmung hinweisen. Wir durften also im Sinne der Kernchentheorie gerade hier erhöhte Werte erwarten, die sich bei frischen Dyspnöen a uch überraschend häufig fanden. Fall 8 stellt eine der höchsten von mir beim Menschen beobachteten Plättchenzahlen vor: verzögerte Grippepneumonie mit einem sehr kleinen interlobären Empyem und dauernder Dyspnöe. Anämisierung, toxischer (septischer) Reiz und

*) Die Vermehrung der Blutplättchen bei der Polycythämie ist bekannt; sie würde der dauernden Mehrbildung von E. entsprechen. Inzwischen fand ich bei einer latent gewordenen Polycythaemia vera Blutplättchen : E. $=254: 1000$ und außerordentlich kernartige Formen. 
die hohen Anforderungen an die verminderte Zahl der Erythrocyten scheinen hier eine besonders lebhafte Regeneration hervorgerufen zu haben, die nichtsdestoweniger infolge des dauemden gesteigerten Verbrauches der E. keine normalen E.-Werte hervorbringen konnte. Relativ betrug die Zahl der Plättchen noch bei 4060000 Erythrocyten $206: 1000$, absolut daher ungewöhnlich hoch 836360 Blutplättchen. Dabei sind die massenhaften Plättchen klein und blaß, d. h. gut abgebaut, Polychrome spärlich, so daß man an eine in physiologischer Form geleistete Mehrlieferung von Erythrocyten (entsprechend etwa der physiologischen Leukocytose) denken mag.

Die schweren dyspnoischen Tbc.-Fälle reagieren ähnlich (Fall 11 und 13). Entsprechend zeigen die klinisch günstigen Tbe.Fälle ohne fortgeschrittene Anämie sogar Erythrocytosen (5 200 000-5 600 000) mit relativ und absolut erhöhten Blutplättchenwerten und vielen plättchenkernigen K.-Formen.

Fall 35 und 38 sind Mediastinaltumoren mit Dyspnöe; Fall 38 hat die höchste beobachtete Zahl von Plättchenkernigen $(35 \%)$ und trotz fast normaler E.-Zahl starke Polychromasie, ein anerkanntes Zeichen starker Erythroregeneration. Hier liegt also sicher ein Zustand, larvierter Regeneration" vor, der durch E.-Verbrauch (Urobilin und Urobilinogen sehr stark positiv!) kompensiert wurde.

Stellen wir diesen Vermehrungen die absoluten Verminderungen der Plättchen in der Tabelle II (s. S. 596) gegenüber, die an sich viel seltener sind, so finden wir bei der Anordnung nach dem relativen Verhältnis Blutplättchen : E. eine größere Unabhängigkeit von der Erythrocytenzahl und eine nur mäßige Übereinstimmung der Anordnung mit den absoluten Werten der Plättchen. Selbst bei selr niedrigem Relativverhältnis finden sich, anscheinend gegen die Theorie, doch hohe E.Zablen. Im histologischen roten Blutbild werden recht oft mit lebhafterer Regeneration die Basophil-Punktierten verzeichnet, die immer auf eine gewisse Schädigung der Erythropoese schließen lassen, und bei niedrigen E.-Werten fallen die vermehrten K.-Formen (Plättchenkernige) ins Auge. Fall 1 fällt so auffallend aus der Gruppe heraus, daß er allein deswegen wohl richtiger in die Tab. III (An. perniciosa) gehörte, wovon ihn der uncharakteristische E.-Befund und der niedrige Hb.-Wert mehr trennte als die Leukocytenverhältnisse. Die anderen Fälle gruppieren sich nach der Ätiologie:

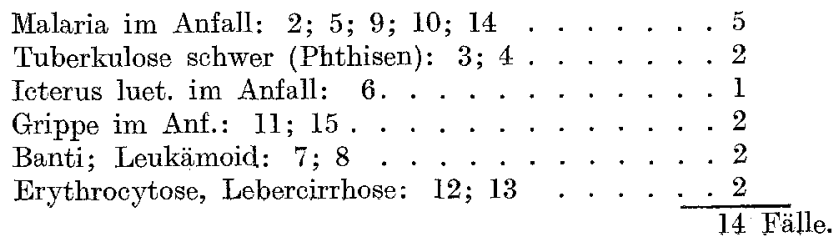


Neunvondiesen 14 Fällen haben mehroder weniger großen Milztumor (Phagocytose, Thrombolyse?). Zehn betreffen akute Infektionen im Anfall (festgestellt schon von Hayem, Denys, Tschistowitsch, Türk, Darling u. a.) oder schwere Phasen chronischer Infektionen. Ein Teil der Fälle z. B. Malaria taucht nach Überwindung des Anfalles unter den absoluten Vermehrungen de. Tabelle I auf.

Stellt man sich den Mechanismus einer einsetzenden Schädigung des Blutes durch eine Infektion usw. vor, so ist die aufgezeigte Unabhängigkeit der E.- und Blutplättchen-Zahlen durchaus plausibel auch für die Kernchentheorie. Man muß bedenken, daß die Hemmung der Erythropoese bei jeder beliebigen Zahlhöhe der Erythrocyten eintreten und jeden beliebigen Grad erreichen kann, ohne da $\mathbf{B}$ sich zuerst die E.Zahlen zu ändern brauchten; erst in der Folge mit Ver. brauch der reifen Elemente w ürde das Absinken der E.-Zahl klinisch in Erscheinung treten infolge Aplasie oder Hypoplasie im Knochenmark. In der Tat führen gerade die vorliegenden Krankheitszustände zu einer sehr bald bemerkbaren Anämie. Nimmt man hinzu, daß nach der Fran kschen Theorie auch die Milz schädigend oder phagocytierend die Blutplättchenzahl noch weiter einschränkt, mehr als nur einer verminderten Erythropoese entsprechen würde, so werden diese Befunde sich unschwer erklären lassen:

Absolute Blutplättchenverminderungen und niedrige Erythrocytenzahlen finden sich recht logisch bei schwereren Schädigungen bzw. Hemmungen der Erythropoese und gehen oft mit auffallend kernartigem Aussehen der Plättchen oder hohen Zahlen der Plättchenkernigen einher. Sie sind, wie es der Plättchenkerntheorie entspricht, in der Regel auch im relativen Verhältnis Blutplättchen: E. ausgeprägt, sind also nicht unabhängig von der Erythrocytenzahl. Auffallende Unstimmig keiten zwischen hohen E.-Zahlen und niedrigen Blutplättchenwerten finden ihre Erklärungdurch periphere Vernichtung von Plättchen in der Milzu. a.

Tabelle III (s. S. 597) vereinigt die Blutplättchenbefunde bei derAnaemia perniciosa Biermer, bei der von Riess, Kemp, Calhoun und Harris, Brockbank u. a. absolute Verminderungen beschrieben waren. Ich habe sie aus der Gesamttabelle herausgenommen, weil sich ganz von selbst bei ihnen ein so eigenartiges Verhalten zeigte, daß sie unter den Verminderungen und Vermebrungen durchaus auffielen. Die Anordnung ist logisch nach der E.-Zahl erfolgt, weil im allgemeinen bei dieser Krankheit aus der E.-Zahl ein leidlicher RüekschIuß auf die Schwere des vorliegenden Anfalles gezogen werden kann. Bis auf Fall 6 und 7 ergibt sich nun 
eine sehr parallele Anordnung der absoluten und relativen Blutplättchenwerte.

Nr.1, eine Remission im guten Zustande, hat als einzige auch absolut übernormalen Wert der Plättchen, wie es ihr als jetzt fast normale (,,sekundäre") Anämie zukam. (Verwendet sind nur absolut einwandfreie länger beobachtete oder ganz typische Fälle, wie die Lenkocytenbefunde unterstützend zeigen.) Nr. 2 war auf der Höhe der wirksamen Therapie. Fall 6 zeigt denselben Fall auf seinem ungünstigsten Tiefstand. Auch Fall 7 ist ein solcher Tiefstand. Letztere beiden abweichenden Fälle mit ihren relativ sehr niedrigen Werten möchte ich zu den Verminderungen der Tabelle II als a kute Exacerbationen der ätiologischen Intoxikation setzen.

Ebenso aufallend wie das zahlenmäßige Verhalten ist auch das histologische Bild, das man kurzalsstärkste Anisocytose der Blutplättchen bezeichnen kann, wieder ein bemerkenswerter Parallelismus mit dem histologisch ganz besonders anisoc ytotischen Perniciosa-E.-Bilde.

[Es sfi hier bemerkt, daß Darling ${ }^{11}$ ) vor allem auf die Verschiedenheit der Plättchen bei den Krankheiten hinwies und eine spezielle Nomenklatur vorschlug, die aber vor der sicheren Herleitung der Plättchen wohl etwas zu weit geht.]

Fassen wir zusammen, so finden wir bei des Anaemia perniciosa ziemlich regelmäßig ein absolutes Absinken der Blutplättchenwerte mit den Erythrocytenzahlen parallel, während es bei den sekundären Anämien fast umgekehrt erscheint. Trotzdem sind sie relativ bis auf Tiefstände vermehrt, was im Gegensatz zu den sehr häufigen relativen Verminderungen sonstiger Anämien mit niedrigen Blutplättchenwerten steht. Wir hätten also im Sinne der Kernchen theorie nach den relativen $\mathrm{Zahlen}$ eine noch bestehende, aber nach den absoluten Werten hinter normalen Regenerationen weit zurückbleibende Erythropoese anzunehmen, eine dauernde toxische Beeinflussung und Störung, wozu die abnormen Erythrocyten-und Blutplättchenbilder vorzüglich passen.

In Tabelle IV (S.598) sind endlich die Purpura-Fälle zusammengefaßt, wieder weil sie ganz aus dem Rahmen herausfielen. Nur bei Fall 1, der auch klinisch eine Besonderheit darstellte und ein Bindeglied zur anaphylaktoiden Purpura zu sein scbien, fehlte eine erhebliche Anämie. Basophile Punktierung als Zeichen der Schädigung der jungen Erythrocyten ist sehr häufig in mäßigem Grade zu finden. Die Entwicklung aplastischer oder torpider Anämien nach oder auch vor den Purpurasymptomen ist bei den neueren Bearbeitern dieses Gebietes (Frank, 
Fonio, Kaznelson, Glanzmann u.a.) stets erwähnt. Ein Milztumor mäßigen Grades war fünfmal nachweisbar. Wenn also auch sehr wohl eine Schädigung des roten Systems unverkennbar ist, so würden die außerordentlich niedrigen Werte der Plättchen doch nicht allein durch das Fehlen des jungen Nachschubes zu erklären sein. Hier bracht man unbedingteine Hilfsh y pothese und diese wurde von Kaznelson ${ }^{34}$ ) (allerdings für die Wrightsche Theorie) in dem thrombolytischen ProzeB angenommen. Sie läßt sich natürlich genau so gut, nach den histologischen Veränderungen der tief pyknotischen Riesenplättchen vielleicht sogar besser, im Sinne der Kernchentheorie anwenden. Die schnelle Gesundung der Plättchen nach der Splenektomie wäre dann darin zu suchen, daß die dauernd stattfindenden Normoblastenentkernungen von diesem Augenblicke an wieder normal erfolgen, ohne daß eine schwer verständliche plötzliche ,Neubildung oder Erholung der Riesenzellen" notwendig wäre.

Klinisch wichtig ist das Ergebnis, daß auch in dieser Auffassung in den Purpura-Fällen mit Thrombopenie eine ganz besondere Gruppe, aber nicht leukocytärer (Frank), sondern erythrocytärer Prozesse zu sehen wäre, die man am einfachsten als eine krankhafteSteigerung desnormalen Kernabbaus der roten Blutzellen ansehen könnte. Die Ursache ist im Sinne Hirschfelds und Franks sehr wohl in einer splenogenen hor monalen Störung eines normal von der Milz beeinfluBten Entkernungsprozesses der Erythrocyten zu erblicken, der gleichzeitig a uf die Erythro poese zurückwirkt. Die bekannten klinischen Purpurabilder stimmen mit dieser Theorie gut überein.

Die angegeben $€ n$ Tabellenbefunde I-IV entsprechen einer weit größeren Zahl von Blutplättchenbestimmungen, die ich in dem gleichen Zeitraum an Kranken aller Art mit Syphilis, Tuberkulose aller Grade, Nervenleiden, Herz-, Magen-, Unfallkranken usw. vorgenommen habe, ohne bei ihnen auffallendere Befunde erheben zu können, wenn nicht gleichzeitig eine anämisierende Wirkung oder Dyspnöe festzustellen war. Der nomale Wert betrug im Durchschnitt 60:1000, der absolute zwischen 250-300 000 im Kubikmillimeter nach der FonioMethode. Trotz normaler Erythroeyten und Blutplättchenwerte konnten hingegen die Leukocytenbefunde histologisch und zahlenmäßig enorm variieren.

Fassen wir die Ergebnisse der klinischen, bistologischen und arithmetischen Befunde zusammen, so ergibt sich:

1. Die Wrightsche Riesenzellenhy pothese ist an sich natürlich durchaus möglich, besitzt und liefert aber keinerlei Stütze für die klinische Wertung. Rechnet man die Riesenzellen zu den Leuko- 
cyten (Decastello und Meissner; Franks Leukomyelotoxikose), so widersprechen m. E. die klinischen Ergebnisse sogar.

2. Die Plättchenkerntheorie stößtnirgends a uf unerklärbare klinische Befunde, stimmt vielmehr im ganzen a uffallend gut zu allen Zuständen der Erythropoese*).

3. Ist die Kernchentheorie richtig, so finden die klinischen Blutplättchenbefunde dadurch eine durchgreifende Klärung. Die Vermehrungen bei Anämien wären als jugend liche Verschiebungen der Erythrocyten =, verstärkte Erythropoese", die Vermehrungen bei normalen und übernormalen E.-Zahlen als ,, larvierte oder la ten te Regeneration“, die Verminderungen vieler Infektionen als ,,gehemmte oder geschädigte Erythropoese", die Schwankungen bei Anaemia perniciosa als „entartete Regeneration“ und die auffällige Verminderung bei Werlhofscher Purpura als „Übersteigerung des physiologischen Kernabbaus und periphere Blutplättchenzerstörung" aufzufassen.

\section{Protoplasmastrukturen.}

Unzweifelhaft müssen die Vorstufen der Erythrocyten als regelrechte Körperzellen ein Exo- und ein Endoplasma haben.

Der Vergleich mit den Leukocyten lehrt, daß diese beiden Teile trennbar voneinander sind und daB in dem strukturierten und festeren Endoplasma bei Lymphocyten und bei jüngeren Leukocyten eine basische, feinnetzige oder feinwabige Grundsubstanz zu sehen ist, über deren reale Beschaffenheit die Protoplasmatheorien noch weit auseinandergehen. Sie sei daher einfach basische jugendliche Substanz oder Spongioplastin (Pappenheim) genannt. Eine von $\mathrm{Pappenheim}$ mehrfach vertretene Analogie gestattet, das $\mathrm{H} \ddot{a}-$ moglobin als ein Äquivalent der Spezialsubstanzen anderer Zellen z. B. der neutrophilen oder eosinophilen Granula der Leukocyten, der Horn- oder Pigmentsubstanzen von Epithelien usw. aufzufassen. Auch bei den Hornsubstanzen begegnen wir z. B. der Möglichkeit einer flüssigen Durchtränkung der ganzen Zelle bei den Vögeln oder einer körnigen Durchsetzung des Protoplasmas bei den Säugern: erstere Form würde der flüssigen $\mathrm{Hb}$.-Spezialsubstanz, letztere der Granulabildung der Leukocyten entsprechen. Es gibt in der Tat keinen prinzipiellen Unterscbied in der Bildung flüssiger und körniger Substanzen bei verwandten Zellformen.

A us diesen Erwägungen folgt die Möglichkeit oder Wahrscheinlichkeit, daß auch der vereinfachte reife Erythrocyt

*) Korrekturanmerkung: Vergleiche die mittlerweile erschienene Arbeit Schilsky, Zeitschr.f. klin. Med. 91, 256. 1921, die zum gleichen Ergebnis auf Grund eines reichen Materials kommt. 
noch seine mehrfachen Hüllen, eine endo- und exoplasmatische Kruste besitztund daß diese dann das flüssige und scheinbar homogene Hämoglobin umschließt. Schon Ha mburger ${ }^{44}$ ) wies darauf hin, daß die Leukocyten (histologisch membranlos) sich gegenüber der Osmose genau so verhielten wie die (angeblich mit einer darstellbaren Membran ausgestatteten) Erythrocyten. Die bei der Hämolyse übrigbleibenden Massen sind allein schon viel zu groß, um anders als eine protoplasmatische Eiweißmasse wie in anderen Zellen gedeutet werden zu können (,Stroma“")*).

Nach diesen Voraussetzungen identifizieren wir also:

a) Membran oder Stroma der Erythrocyten mit Exound Endoplasma anderer Zellen.

b) Jugendliche Basophilie der Erythrocyten mit jugend. lichem Spongioplastin der Zellen.

c) Hämoglobin mit Spezialsubstanzen bzw. Sekretionsprodukten anderer Zellen.

a) Kruste oder Stroma. Die klinische Bedeutung dieser Strukturteile ist unzweifelhaft, aber schwer morphologisch nachzuweisen. Immerhin kann man die Pachydermie der Erythrocyten bei hämolytischen Anämien [Itami und Pratt范)] vom Standpunkt der Zelltheorie recht gut als einen biologisehen Anpassungsprozeß lebender Zellen an vermehrte Belastung auffassen und nachforschen, ob nur die Vorstufen des Erythrocyten oder auch noch die zirkulierenden Erythrocyten lebensfähig genug sind, um derartige Anpassungen vollziehen zu können. Diese ganze Frage hängt sehr nahe mit der Cholesterineinlagerung im Erythrocyten zusammen, die gerade nach neueren Untersuchungen großen Schwankungen unterworfen sein kann [Rosenthal ${ }^{46}$ ) u. a.]. Da Cholesterin mindestens teilweise eine exogene mit der Nahrung eingefübrte Substanz zu sein scheint, ist es sehr interessant, festzustellen, ob die Vera n ker ung physikalisch durch Adsorption oder Resorption oder biologisch als cellulärer ProzeB erfolgt, zumal dadurch die therapeutische Verabreichung von Cholesterin als Schutzmittel gegen Hämolysen unter ganz verschiedenen Gesichtspunkten erscheint.

Noch wichtiger wäre die Feststellung, ob etwa der kernlose Erythrocyt seinen Hb.-Gehalt dire kt ergänzen kann oder ob dazu, was wahrscheinlicher ist, stets die Zelltätigkeit der kernhaltigen Vor-

*) Dieser Auffassung entspricht im ganzen das Ergebnis feinerer kolloidchemischer Untersuchungen von Bechhold (M. M. W. 5. 1921), der, ohne anscheinend die morphologischen Erythrocyten Struktur-A rbeiten zu kennen, ein feinnetziges, oberflächliches, kompliziert aufgebautes „Stroma“, aber keine „Membran" im Weidenreich'schen oder Dietrich'schen Sinne gefunden hat. 
st ufen notwendig ist. Es besteht ein sehr auffallender Gegensatz bei der Regeneration hämolytischer, im Körper sozusagen geschlossen erfolgender Blutzerstörungen und den nach außen hin das Blut entleerenden Blutverlustanämien, und es ist noch sehr strittig, ob die Blutschlacken lediglich als stärkerer Anreiz oder direkt als Bau material für die jungen Generationen dienen. Auffällig ist, daß gerade diese toxischen Anämien so oft mit erhöhten $\mathrm{Hb}$.-Werten einhergehen, während die hämorrhagischen Anämien der Oligochromasie zuneigen

Von fundamentaler Bedeutung wird diese Frage für die A ufklärung des Ehrlichschen „e mbryonalen Rückschlages“ der Er ythro poese. Daß lebende Zellen sich unter Reizen vergrößern oder verkleinern können, bedarf nicht erst der Diskussion. Wenn aber der Erythrocyt oder seine Vorstufe in der Lage ist, seine spezifische Hb.-Substanz durch Neubildung oder Resorption zu vermehren, so ist die Entstehung großer vermehrt $\mathrm{Hb}$.-haltiger oder hyperchromer Elemente nicht mehr etwas ganz Besonderes, sondern die einfache Folge einer starken und dauernden Reizung und eine Anpassung an die schwere Anämie. Derartige funktionelle Hypertrophien kennen wir an Epithelzellen z. B. auf Druck, ehemische Reizung usw., ohne daß wir hier von embryonalem Rückschlag sprechen. Tatsächlich läßt sich die Megaloblastose viel besser mit derartigen reparablen Prozessen vergleichen, nachdem die ursprüngliche Vorstellung einer irreparablen perniziösen Entartung der Erythropoese durch die Heilbarkeit ganz gleicher Blutbilder bei Botrioeephalus, Lues, Gravidität, Sprew u. a. abgewiesen ist. Damit käme man also auf die von Pappenheim, Grawitz, Verfasser u.a. gegenüber Ehrlich und Naegeli vertretene Auffassung, daß das megaloblastische Blutbild die letzte Etappe einer jeden geeignet einwirkenden Blutschädigung sein könnte und nur zuerst zufällig beim Morbus Bier mer von Ehrlich gefunden wurde, weil es hier in der Tat fast stets zur Entwicklung kommt. Perniziös (klinisch) sind aber nicht die Megaloblasten, sondern der Morbus Biermer. Diese Auffassung ist insofern sehr wichtig, als Naegeli2) noch heute die Krankheiten mit einem dem Morbus Biermer gleichen Blutbild trotz ihrer zugegeben vielfachen Ätiologie als perniziöse Anämien zusammenstellt und das Vorkommen echter Megalocytose allein in dieser Gruppe gelten läBt. Das Gemeinsame dieser Gruppe ist sicher sehr wahrseheinlich und wird durch das $\mathrm{Na}$ a gelische S y ndro m: gleichzeitige Leukopenie, Lymphocytose, Schädigung der Monocyten, Blutplättchenverminderung, Kernverschiebung nach rachts trefflich gestützt, weist aber auf eine höhere, vielleicht endokrine, nicht aber blutmorphologische Einheit im Ehrlichschen Sinne hin. Da Erythrocyten- 
und Leukocytenveränderungen durchaus eigene Wege gehen können, ist die Beschränkung der Megalocyten gerade auf diesen Perniciosakomplex keine Notwendigkeit und meines Erachtens durch zahlreiche Befunde der Literatur unwahrscheinlich, in denen zwar kein Naegelisches Syndrom, wohl aber eine Megalocytose vorlag.

Weitere interessante Anwendungen bietet der hämolytische Ikterus, bei dem nach Naegeli eine ganz eigene Art kleiner kugeliger scheinbar hyperchromer Erythroeyten vorkommen soll. In der Tat sind diese zu finden, bedeuten aber nach der cellulären Theorie des Erythrocyten nur eine rote Zelle, die infolge einer Schwächeihrer Stützsubstanzselbstim physiologischen Plasma schon aus der Scheibenform in die prähämolytische rundlichere Form übergeht; wenigstens kann man genau identische Erythrocyten im Beginne der Hämolysen auch im normalen Blut finden, wenn man es mit hypotonischen Lösungen verdünnt. Die Abweichung könnte allerdings auch in einer geringen physikalischen Abänderung der lipoiden stromatischen Substanz liegen. Solche angeborenen oder erworbenen ganz speziellen Defekte sind uns beim Epithel vielfach bekannt geworden (z. B. für Pigment als Vitiligo, Albinismus, pigmentloses Narbengewebe), obne daß wir von ganz neuen Zellen sprechen würden.

Diese Fragen sind noch im Beginn ihrer Bearbeitung, doch scheint mir ein Hinweis auf die Zellnatur des Erythrocyten brauchbar, weil er eine Reihe neuer biologischer Gesichtspunkte eröffnet und dazu beiträgt, abweichende Erythrocytenformen oder Eigenschaften nicht wie bisher als etwas Isoliertes, nur Erythrocyten Zukommendes, sondern als Glied in einer verfolgbaren Kette biologischer Zellprozesse zu werten, was besonders für die Klinik notwendig und mit Naegelis allgemeiner gehaltenen biologischen Gesichtspunkten durchaus vereinbar ist.

b) Basische Substanz. Der seit Ehrlichs ${ }^{1}$ ) Entdeckung um die basische Färbbarkeit mancher anämischer Erythrocyten entbrannte Streit neigt sich dem Ende zu. Die degenerative Deutung ist fast allgemein der Anerkennung als Zeichen der Jugendlichkeit gewichen, da allzu einleuchtend die Vorstufen der Erythrocyten im Knochenmark und beim Embryo das basische Spongioplastin zeigten. Obgleich das lytische Verschwinden dieser Substanz mit allen Ưbergängen bis zum kernlosen orthochromatischen Erythrocyten verfolgt werden kann, halten einige Autoren immer noch an der Angabe fest, daß durch längeres Aufbewahren von extravasiertem Blut, bzw. im Körper eine identische echte Polychromasie entstehen könne. Diese 
Behauptung enthält die klinische Unsicherheit der Beurteilung, da dann immer noch die Folgerung übrigbleibt, daß z. B. bei gewissen aplastischen Anämien beobachtete Polychrome degenerative Erythrocyten gewesen wären. Vom Standpunkt der Zellnatur des Erythrocyten ist zu sagen: So gewiß wie in den oberflächlichen, der Abstoßung zuwachsenden Epithelzellen das a uch hier in den jüngsten Schichten vorher vorhandene Spongioplastin nicht restituierbar ist, so sicher kann auch ein orthochromatisch gewordener Erythrocyt nicht in seine spongioplasmatische Vorstufe zurückkehren. Oder man müßte dem reifen Kernlosen eine ganz regenerationsfähige Zellnatur zusprechen, wie sie selbst die hier vorgetragene Auffassung nicht im entferntesten für möglich hält. Was als wiederauftauchende degenerative „Polychromasie" beschrieben wird, ist lediglich eine veränderte Färbbarkeit ( = Metachromasie) der zugrunde gehenden Erythrocyten ohne feinere Ähnlichkeit.

Als absolutes leicht nachweisbares Jugendzeichen ist die Polychromasie eins der besten Mittel zur klinischen Bewertung eines anämischen $\mathrm{Zustandes,} \mathrm{im} \mathrm{Ausstrich} \mathrm{aber} \mathrm{keineswegs}$ immer leicht zu erkennen, vor allem bei den heute üblichen Doppelfärbungen nicht, die durch Eosin eine schwacke Polychromasie ganz überdecken. Es ist daher von praktischer Bedeutung, daß die neueren Arbeiten die von Biondi, Sabrazès, Pappenheim, Verfasser vertretene Identität der sogenannten ,Substantia granulofilamentosa“, der vitalfärbbaren blauen Netzstruktur junger Erythrocyten, mit Polychromasie wobi erwiesen haben. Die Netzstruktur ist einfacheine vergröberte, koagulier te, a usgefällteErscheinungsform des Spongioplastins=Polychromasie, das auch in seiner.ursprünglichen Beschaffenheit, wie der Name sagt, eine fasrige, feinwabige oder schaumige Struktur gehabt hat. Die Beobachtung genau der gleichen Substanz in jungen Leukocyten und Lymphocyten, die gleiche ab und an sehr schön nachweisbare Netzstruktur in ihnen im Vitalpräparat, sind gegen die letzten Zweifel anzuführen.

Geradediese ,vitale" Erscheinungsform nehmen nun a uch die Polychromen im ,dicken Tropfen"-Präparat unter dem Einfluß der Hämolyse durch die Farblösung an und sind nun im klaren Untergrunde der glashellen orthochromatischen Schatten als zarte blaue Netzchen erkennbar, viel besser und zahlreicher als im Ausstrich. Da der reifere Mensch normal nur ganz verschwindend. Polychrome besitzt, genügt ein Blick in ein gut gefärbtes Tropfenpräparat, um Vermehrungen und ihre $\mathrm{Zu}$ - und Abnahme von Tag zu Tag zu registrieren. Die praktische Anwendung zeigen die Malaria- 
kurven IV und V, Abb. 9 u. 10, S. 570, bei denen das Auftreten der Polychromasie so verfolgt und durch,,++++++ usw. eingetragen ist (s. auch die anderen Kurven).

Die scharf erkennbare. Netzform der basischen Substanz erlaubt auch die normal ganz allmähliche Lysisim Hämoglobinteil des Proto plasmas zu verfolgen [Verfasser ${ }^{4}$ ), Naegeli $\left.\left.{ }^{2}\right)\right]$.

Untersuchen wir nun, gestützt auf die Spongioplastin-Natur dieser Erscheinung und eingedenk, daß wir reifende Zellen vor Augen haben, das Blut von Anämikern regelmäßig im dicken Tropfen, so fallen sehr bald eigenartige Verschiedenheiten der Netzchen auf, die bei einigen Fällen durchweg ein gröberes, ja ein direkt zerrissenes grobflockiges Aussehen annehmen können. Ich bezeichne diese Form gegenüber der zarten feinfädigen Polychromasie als ,zerrissene Netzsubstanz" und sehe in ihr den einfachsten Aus: druck einer Proto plasmaschädigung der sich regenerierenden Zellen, die auf geschädigtem Abbau des Spongioplastins beruht. Die Erscheinung ist so auffällig, daß sie mich wiederholt auf das Bestehen einer besonderen Ätiologie der Anämie aufmerksam machte, wo man sonst an einfache Begleitanämie gedacht hätte. Ich führe hier nur an: angebliches Ulcus ventriculi, das nachher als $\mathrm{Ca}$. pyiori, gastrische Anämie, die als Bleivergiftung, und Rekonvaleszenz - Anämie nach Grippe, die als latente Sepsis erkannt wurden.

Diese gröbere zerrissene Polychromasie leitet im „dicken Tropfen" ohne weiteres über in eine dritte Form der basischen Er ythrocytensubstanz, die als baso phile Punktierung bezeichnet wird, wenn man sie im Ausstrich findet. Sie zeichnet sich im ,dicken Tropfen" durch ein punktförmiges feintropfiges Aussehen der einzelnen blauen Teilchen aus und ist sonst wie die Netzsubstanz in rundlichen Gruppen angeordnet, die dem hämoglobinfreien Schatten des basophilpunktierten Erythrocyten entsprechen. Mit dem dicken Tropfen gelingt es nun viel leichter als mit der Ausstrichtechnik, die feinsten Ubergänge zwischen der Polychromasie und den basophilen Punktierungen, häufig eben in Form der zerrrissenen Polychromasie, zu entdecken und klinisch zu verfolgen, wie Verfasser ${ }^{47}$ ) für Malaria besonders angab.

Der dicke Tropfen ist also ein leicht zugängliches Beweismaterial für den Satz, den Verfasser ${ }^{4}$ ) auf Grund ähnlicher Vorstellungen von Pappenheim, Askanazy u. a. gegenüber der karyogenen Theorie der basophilen Punktierung [zuletzt Naegeli ${ }^{2}$ ), König ${ }^{48}$ ), Ferrata $\left.{ }^{49}\right)$ ] und sicher gestützt auf die Zelltheorie 1911 aufstellte: 
Polychromasie, basische Netzstruktur und basophile Punktierung sind substantiell identische morphologische Modifikationen der gleichen basischen $\mathfrak{J}$ ugendsubstanzim Protoplasma des Erythrocyten. Die basische Netzsubstanz ist nur eine andere Erscheinungsform der Polychromasie, bedingt durch die Technik der unfixierten Färbung, klinisch daher durchaus gleich zu werten. Basophile Punktierung bedeutet dagegen eine degenerative (beim Embryo allerdings physiologisch vorkommende) pathologische Verklum pung oder tropfige Umwandlung, die klinisch fast ausnahmslos auf toxische Schädigung der Erythropoese deutet und daher von der physiologischen Polychromasie der Anämien zu unterscheiden ist.

Nach einer während der Niederschrift eintreffenden umfangreichen Publikation von Negreiros-Rinaldi50) unter Leitung Ferratas ist die karyogene Genese der Basophilie auch dort jetzt abgelehnt und die Ableitung vom Spongioplastin genau im Sinne des Verfassers*) a nge no m men worden **). Die Behauptung, daß Verfasser die basischen Substanzen für absolut identisch gehalten und die Möglichkeit der Umwandlung von vitalgefärbter Netzsubstanz in basophile Punktierung angenommen habe, ist ein Irrtum. Verfasser hat dagegen experimentell gezeigt, daß man polychromatische Erythrocyten entweder in vitale Netzstruktur oder in basophile Punktierung verwandeln kann (Schlußsatz 5, Arb. über die Erythr. I Fol. baem. Arch. XI., S. 370), daß aber die einmal durch Auftropfung aus der Polychromasie gebildete Punktierung auch in der Vitalfärbung als Punktierung oder ganz grob zerrissenes Netz erscheint.

Die noch dagegen angeführte Ansicht, daß nur ein zufälliger Parallelismus im Regenerationsprozeß vorläge, indem manche Erythrocyten polychrom, andere mit Netzsubstanz ausgestattet neu in das periphere Blut gelangten, ist leicht widerlegbar. Die stets höhere Zahl netzig Strukturierter erklärt sich einfach durch die bessere Sichtbarkeit der feinen Netzchen oder der letzten blauen Fasern, doch wird bei guter Methylenblaufärbung der Zahlenunterschied schon sehr gering. Daß es genau die gleichen Zellen sind, bewies mir erst gerade wieder ein An. perniciosa-Fall, der nur ganz s pärliche riesige polychrome Megalocyten neben ganz vereinzelten

*) Pappenheim ${ }^{3}$ ) bestreitet noch zuletzt die substantielle Identität, indem er fälschlich substantiell $=$ morphologisch satzt.

**) Korrektur - Anmerkung: Kreibich leitet (Berl. Klin. W. 1921, S. 695) die basophilen Punkts wieder vom Kern ab, ohne die Fülle des entgegenstehenden Materials irgendwie zu würdigen. 
polychromen normalen Erythrocyten hatte. Im dicken Tropfen fielen sofort diese Megalocyten als große blaue Netzfigürchen neben ganz vereinzelten normalen Netzchen ins Auge (Taf. III, c). Auch das Vorkommen von parasitoiden Kernkugeln mit blauer Grundplatte in polychromen Megalocyten korrespondierte vollkommen. Daß man die polychromen Megaloblasten im dicken Tropfen dagegen kaum von den breitleibigeren Lymphocyten unterscheiden konnte, spricht nur für die vollkommene Analogie der basischen Netzstruktur mit dem Spongioplastin junger Leukocyten.

Die Zelltheorie bestätigt und sichert daher die klinische Wertung der basischen Protoplasmasubstanz junger Erythrocyten als Maßstab physiologischer (Polychromasie bzw. Netzsubstanz), pathologischer (basophile Punktierung) oder fehlender (Nichtvorhandensein basischer Substanzen in dickem Tropfen) Regeneration der Erythrocyten. Die basophile Punktierung hat dabei trotz ihrer histologisch-degenerativen Entstehung klinisch u. U. eine günstigere a uf Besserung hinweisende Bedeutung, da ja gerade imSinne derZelltheorie $\mathbf{n}$ ur $\mathbf{j}$ u n ge s pon gio pla s ma tische Erythrocyten in dieser Form entarten können, während alle Behauptungen degenerativer Entstehung im or thochromatischen(!) Erythrocyten als unwahrscheinlich abzulehnen sind. So fehlen die basophilen Punktierungen logisch bei schwerer Hemmung oder Aplasie der Erythropoese, bzw. finden sich dann nur noch im Knochenmark [Walterhöfex $\left.\left.{ }^{51}\right)\right]$, nehmen aber zu bei den ersten Besserungen toxischer Anämien z. B. bei Malaria [P. Schmid t52)] zugleich mit der Polychromasie, die bei Beseitigung der toxischen Einwirkung dann schließlich allein das Bild beherrscht.

Wer auch jetzt noch an der substantiellen Identität der drei basischen Erscheinungsformen des Spongioplastins zweifelt, müßte den Verbleib der Polychromen im dicken Tropfen nachweisen und die beschriebene zerrissene oder die punktför mig aufgelöste basische Erscheinungsform der Netzchen als eine neue pathologische Veränderung der Erythrocyten zugeben, wozu m. E. kein Anlaß vorliegt, da Polychromasie und basophile Punktierung im Ausstrich parallel geht.

c) Hämoglobin-S pezialsubstanz. Mit dem Hämoglobin als Strukturteil haben wir uns oben schon anläßlich der Besprechung der Stromavergrößerungen beschäftigt. Eigentlich ist jedoch der Hämoglobinteil des roten Blutkörpers ebenso von der protoplasmatischen Grundstruktur zu trennen, wie das Granuloplasma im Leukocyten als ein zusammenhängender Zellteil innerhalb des Endoplas mas besonders in gequollenen [Verfasser ${ }^{53}$ ) im Dun kelfeld] oder 
in pathologisch geschädigten Zellen erwiesen werden kann. Sehr schön zeigen oft Monocyten der An. pern. diese Zusammenziehung ihres azurophilen Granuloplasmas auf einen perinuclearen Bezirk, umgeben von einem graublauen Endoplasma und einem klaren hellblauen, Pseudopodien bildenden Exoplasma (Textabb. 12). Auch leukämische Leukocyten zeigen die Entstehung der Granula in besonderen perinuclearen bzw. archoplasmatischen Bezirken der jüngsten Vorstufen besonders klar, während sich bei den reifen Elementen die Granuloplasmen vor den Teilungen korrespondierend mit allen Zellteilen vergrößern und, bei der Teilung halbiert, fertig ausgebildet auf die Tochterzellen übergehen.

Hämoglobin und Endoplasma sind also entgegen der Weidenreichschen Definition nicht gleichbedeutend, obwohl

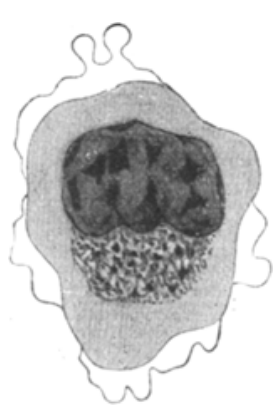

Abb. 12. Monocyt bei Anämia perniciosa. Sonderung des Ekto-, Endound Granuloplasmas im Trockenausstrich. das Hämoglobin in reifen Zellen $\epsilon$ doplasmatischer Bestandteil ist.

Diese subtile Erörterung erschien notwendig, da i $\mathrm{m}$ Hämoglobin klinisch wichtige körnige Strukturen vorkommen können, deren Erklärung histologisch schwierig ist. Vor allem ist das bei Phenylhydrazin- und verwandten Vergiftungen beschrieben worden (Ehrlichs hämoglobinämische Innenkörper). Diese Körnchen sind augenscheinlich resistent gewordene $\mathrm{Hb}$.-Teile, wie ihre Farbe, Eosinophilie und ihre Erhaltung bei Hämolyse zeigt. In ihrer feinsten Form können sie der azurophilen Schüffnertüpfelung der Malaria-Tertiana-Erythrocyten ähnlich sehen, die ebenfalls ein relativ resistenter und $u$. U. im dicken Tropfen noch Hb.-haltiger Strukturbestandteil geschädigter Erythrocyten sind [s. Werner u. Verfasser $\left.\left.{ }^{4}{ }^{a}\right)\right]$.

Im Gegensatz zu den basischen Erythrocytensubstanzen können diese Strukturen a uch noch am reifen orthochromatischen Erythrocyten erzielt werden, was nicht immer beachtet wurde (Taf. III, f).

Versuchen wir die Erklärung von der Zelltheorie aus, so ist es durchaus plausibel, daß uns hier durch die pathologische Einwirkung Grundstrukturen sichtbar gemacht werden, die sonst nicht darstellbar sind. Gerade die Regelmäßigkeit der Schüffnertüpfelung legt diesen Gedanken so nahe, daß Maurer ${ }^{54}$ ) an ein sichtbar werdendes Rollettsches Stroma und Schaudinn ${ }^{55}$ ) an Manifestation chromidienartiger Zellstrukturen dachte, die den fehlenden Kern ersetzen könnten. Modern würde man wohl eher von Mitochondrien reden, von denen ja nach vielfacher Ansicht 
die Ausbildung der Spezialsubstanzen ausgeht. Diese mitochondrialen Endoplasmastrukturen sind also wieder nicht identisch mit Hämoglobin, sondern nur mit Hb. getränkte oder vielleicht auch Hb. noch produzierendeZellorganellen, die nun durch pathologische Veränderungen im Hämoglobin sichtbar werden. Es scheint also möglich, mit Hilfe der Zelltheorie Erklärungen für diese sonst rätselhaften und isolierten Erscheinungsformen der Erythrocyten zu finden, die uns bei ihrer klinisch-diagnostischen Beurteilung helfen und uns nebenbei auch noch über das Wesen der $\mathbf{H b}$. - Bildung selbst unterrichten könnten.

Wir werden auf diese Strukturen noch einmal im nächsten Absatz zurückkommen.

\section{Der Archoplasma-Teil.}

Archoplasmen sind in der neueren Histologie bekannte Zellstrukturen von paranucleärer und zentraler Lage, besonders abgegrenzte und chemisch differente Protoplasmabezirke in der näheren Umgebung des Centrosoms, die erst nur in hochentwickelten. Zellen, z. B. der Spermatogenese, zunehmend aber auch in allen Arten von Körperzellen nachgewiesen werden konnten. Die Zellauffassung des Erythrocyten legte es nahe, auch diese oft sehr veränderlichen und merkwürdigen Gebilde mit in den Kreis der Betrachtung zu ziehen, wo die einfache Sonderung in Kern und Protoplasma unbefriedigend erschien. Die Benennung dieser Strukturen in der normalen Histologie ist eine sehr verschiedene, je nach dem studierten Objekt, dennoch kehren vergleichbare Anordnungen stets wieder and ließen sich im Erythrocyten wiederfinden:

a) Eine glasklarezentrale Masse (Hof oder Protoplasmabezirk), die den Kern oft exzentrisch verlagert und im allgemeinen als Rest der Astros phäre beschrieben wird. Sie hebt sich besonders in granulierten jungen Leukocyten, in Plasmazellen (s. Abb. I b, nach Axel Walgreen) und auch in polychromen Erythrocyten gut ab, bleibt aber auch $\mathrm{m}$. E. in den reiferen Zellen mit ihrer weißen Grundmasse unsichtbar erhalten, wie gelegentliche Präparationen zeigen. Diesen Teil nannte ich Glaskörper [Verfasser $\left.{ }^{a}\right)$ ].

b) Ein schärfer, meist deutlich kör perlich begrenzter Innenbezirk von abweichender chemischer Beschaffenheit und großer Variabilität unter pathologischen Einflüssen oder während physiologischer Zellwandlungen, der als eigentliche S phäre, als Idiozoma usw. beschrieben wird und in naher Beziehung zum Golgi-Apparat stehen dürfte (Abb. 1, K). Auf, in oder neben ihm findet man in der Regel, doch nicht untrennbar mit ihm verbunden das Centroso $\mathrm{m}$, bestehend aus den eigentlichen Zentralkörnern (Centriolen) und einer Verbindung 
oder Hülle um sie (Abb. 1, C). Die Körnchen sind stark azurophil, die Grundplatte basophil, die Hülle kann chromatisch werden. In dem körperlick abgegrenzten Teil, dem ich wegen seiner Form und in Anlehnung an histologische Benennungen den Namen "Kapselkörper" beilegte als indifferente Bezeichnung, können blaue plastische Substanzen und auch feine azurophile Strukturen auftreten, besonders wichtig ist aber sein Gehalt an lipoiden Stoffen, die für die technische Darstellung, die Farbreaktionen und auch für die Labilität der Erscheinungsformen physiologisch und pathologisch eine bedeutende Rolle spielen.

Die Einführung des Kapselkörpers hat einen neuen Weg zur Klärung der „Nucleoide“" gewiesen, die Naegeli²) und Weidenreich ${ }^{6}$ ) allerdings a uch heu te noch als Kunstprodukte oder Täuschungen ansehen, die nach zahllosen verschiedenartigsten Techniken dennoch als vorhanden anzunehmen sind.

Roberts beschrieb zuerst bei Behandlung des Blutes mit Magentaund Tanninlösung ein kleines, aus dem Erythrocyten ausstoßbares Bläschen. Dieses ist nach meinen Untersuchungen identisch mit den angeblichen Kernen der Erythrocyten von Boettcher, King, Kron berger u. a., mit den Nucleoiden oder Kernresten Lavd owskys, Arnolds, Maximows, Giglio-Tos', Hirschfelds, Pappenheims, Petrones, mit den Ehrlich-Heinzschen hämoglobinämischen Innenkörpern, teilweise mit den Schmauchschen Körpern, mit den Schistocyten (auch im freien Zustande) und mit dem hämeglobinogenen Körper von Giglio-Tos, Negri, Petrone, Pighini*). Die Begründung für diese Annahme habe ich in meiner Arb. ü. d. Erythr. IV. Fol. haem. Arch. XIV. gegeben.

Die Verschiedenheit der Beschreibungen erklärt sich aus der Tatsache, daß der Kapselkörper im nor malen polychromen oder or thochromatischen Erythrocyten wegen seiner völligen Durchtränkung mit $\mathrm{Hämoglobin} \mathrm{gänzlich} \mathrm{verschwindet} \mathrm{und} \mathrm{auch}$ im Dunkelfeld ebensowenig nachweisbar ist wie z. B. Golgikörper der Spermatogonien, die doch gut darstellbare Strukturen sind. Das optisch leere Aussehen im Dunkelfeld ist natürlich nicht der geringste Gegenbeweis, obgleich er oft angeführt wird (Dietrich u. a.). Das Körperchen besitzt eine eigene li poide Hülle, die ihm im allgemeinen etwa die gleiche Resistenz verleiht wie dem ganzen Erythrocyten, bei toxischen Anä mien aber, ebenso wie die E.-Resistenz, durch wahrscheinlich lipoide Einlagerungen gesteigert wird, und zwar häufig stärker, so da $B$ n un bei schonenden Hämo.

*) Die speziellen Arbeiten sind in meiner früheren Arbeit IV zitiert [Verf. $\left.{ }^{4}\right)$ ]. 
lysen das Körperchen erhalten bleibt, wenn der Erythroeyt bereits zerstötwird. Diese Lipoide verleihen dem sonst oxyphilen Gebilde gleichzeitig eine besonders in Vitalfärbungen hervortretende abnorme Darstellbarkeit, so da $\beta$ es nun bei Ausstrichfärbungen durch seine verstärkte Oxyphilie (Schistocyten, kompakte hämoglobinämische Innenkörper), in Vitalfär bungen durch Basophilie (Heinz-, Schmauchsche Körper) wie etwas ganz Neues in Erscheinung tritt. Wird die pathologische Abwandlung noch stärker, so treten auch im Ausstrichpräparat plastinoide bläuliche Färbungen auf und schaffen wieder anscheinend neue Gebilde. Daß aber auch eine gewisse chemische Verschiedenheit schon dem normalen Erythrocyten gegenüber besteht, beweisen die Darstellungsmöglichkeiten mit den intensiven Spezialfärbungen von Reddingius, Pappenheim u. a., die Eisenhämatoxylin-Differenzierungen [Verfasser $\left.\left.{ }^{4}\right)\right]$ u. a.

Natürlich besteht bei toxisch-anämischem Blut leicht der Verdacht von partiellen Protoplasmaschädigungen [Ehrlich $\left.\left.{ }^{1}\right)\right]$, obgleich ibre scharfeBegrenzung und ihre charakteristischeAnordnung imErythrocyten nicht recht erklärlich scheint. Um so wertvoller sind die zuletzt erwälnten Färbungen am normalen Blut, aber sie zeigen leider nicht eindeutig. genug die körperliche Isolierbarkeit des Gebildes. Deswegen möchte ich hier eine neue, außerordentlich einfache Technik abbilden, die mir an drei in Konstantionpel eingefangenen herrenlosen Katzen*) schöne Präparate lieferte. Das Blut der anscheinend normalen, nur etwas anämischen noch jungen Tiere wurde einfach ausgestrichen, im Brutschrank 24 Stunden getrocknet und ohne Fixierung mit Giemsalösung (1 Tropfen auf $1 \mathrm{ccm}$ Aqu: dest.) übergossen. Nach 20 Minuten wurde vorsichtig gespült, getrocknet und in Cedernöl betrachtet. Jetzt zeigten alle Erythrocyten weiter Bezirke in jedem enthämoglobinisierten Schatten ein hämoglobinhaltiges Körperchen mit einem oft sehr deutlichen Chromatinkorn. Als ich die Tiere mit schwachen Phenylbydrazinlösungen etwas anämisierte, traten auch größere polychrome Makrocyten auf, die nun neben dem Körperchen von etwas blasserer $\mathrm{Hb}$.-Farbe auch noch das Spongioplastin in Form der Netzstruktur und den archoplasmatischen Hof (Glaskörper) in zierlicher Anordnung zeigten, d. h. ein vollständiges Bild der theoretischen Zellstruktur des kernlosen Erythrocyten lieferten (Taf. III, g u. h).

Diese mit einer Täuschungen wohl ausschließenden sehr einfachen Technik gewonnenen Bilder bewiesen also die gleiche Struktur in an-

*) Bei Katzen besteht auch pathologisch größte Neigung zur Heỉn - Körperausbildung. Sie wird dann mit Nilblau leicht darstellbar. 
scheinend gesunden Erythrocyten, die ich bereits in pathologischen Erythrocyten in derberer Form nachgewiesen hatte (Verfasser, Centralblatt f. Bakteriolngie Orig. 63. 400. Farb. Tafel $\left.1,{ }^{1-16}\right)$. Die damaligen Befunde erlaubten nun auch die Genese dieser Körperchen, die schon von Negri, Bremer u. a. als durchaus paranucleär in Kernhaltigen beschrieben waren, weiter zu klären. In der abgebildeten Serie von Normoblasten und Polychromen ist dieses Verhältnis sehr klar ersichtlich. Kerne oder Kernreste sind die Körperchen sicher nicht, obgleich sie in sehr jungen Stadien, wie das von vielen Archoplasmastrukturen behauptet wird, chromidienartige Beziehungen zum Kern zu haben scheinen. Leitet man doch in der Protozoologie den gesamten Nebenkern- und Geißelapparat, der dem Centrosom und seiner Umgebung entspricht, teilweise vom Hauptkern ab. Diese Vorstellung ist aber eine gänzlich andere, wie sie im allgemeinen mit dem Nucleoidbegriff (Rest eines aufgelösten Kernes) verbunden wurde. Nach der vorläufigen Annahme der hier vertretenen Theorieist der eigentliche Kern ja in der Form des PlättchenkernesausderZelle physiologisch enucleiert worden, und der Kapselkörper ist nieht ein Kernrest oder Kernersatz, sondern eine paranucleäre Struktur wie der Nebenkern dauernd kernhaltiger Zellen. Allerdings mag er, wie der Nebenkern, für die Organisation der Zelle und für ihre vegetative Existenz große Bedeutung haben.

Ebenso werden auch dem Archoplasma wichtige Funktionen für das Protoplasma von der Histologie zugewiesen, die allerdings noch nicht durchgreifend geklärt sind. Wahrscheinlich nehmen die „Ergastoplasma" genannten lipoidhaltigen und teilweise azurophil gefärbten Strukturen von diesen zentralen Bezirken ihren Ursprung und verbreiten sich erst dann im Protoplasma, dort die eigentlichen Spezialsubstanzen ausarbeitend. Vereint mit den Kernbeziehungen kann man von einer vermittelnden Rolle der Archoplasmen im Stoffwechsel zwischen Kern und Zelle sprechen. Wie verwickelt die Prozesse sind, lehren die schönen Diktyosomen-Zyklen, die Perroncito ${ }^{56}$ ) bei der Spermatogenese der Paludina vivipara nachgewiesen hat und die regelmäßige mitoseartige Teilungsstadien der archoplasmatischen Golginetze vor und mit der Karyokinese erkennen lassen. Etwas einfacher sind die auch in dieses Gebiet gehörigen Pigmententstehungen aus anscheinend ursprünglich karyogenen, aber im Archoplasma wachsenden und dureh chemische Änderung schließlich in Pigment übergehenden Strukturen, die besonders Meirowsi studiert hat.

Wenn auch vorläufig erst in den Anfängen, so zeigen sich doch schon klinische Nutzanwendungen aus den Veränderungen der Innenkörper. 
Durch die chemischen Studien von Friedstein 57 ), Pappenheim and Zuzuki58), Hartwich ${ }^{59}$ ), Kunkel ${ }^{60}$ ) und Heuer ${ }^{61}$ ) war die $Z$ usammensetzung der eigenartigen Gebilde weitgehend a ufgedeckt worden. Zu dem bereits von Ehrlich nachgewiesenen Methämoglobin war die Gegenwart einer beosnderen z weiwertigen Ferroform und Peroxydasereaktion (Hartwich), der Hauptgehalt an einer histonartigen Eiweißsubstanz (Syntonin nach Kunkel), von etwas Cholesterin (Kun kel) und anderen Fettkörpern erkannt worden. Wir erfahren hier zum ersten Male etwas Genaueres über die Substanzen, die unter pathologischen Verhältnissen in ganz isolierten Organteilen von Zellen sich ansammeln. H. Müller ${ }^{63}$ ) erwies durch neuere Fettfärbungen eingehender den Lipoidgchalt und kommt aus den Massenanteilen und dem histologischen Bilde zu dem wichtigen Schluß, daß (ganz entsprechend meiner von ihm erst gestreiften Zelltheorie) es sich um Verbreitung der Lipoide auf der Oberfläche der Innenkörper handelt, was sich mit meiner Bezeichnung ,Kapselkörper" deckt. Hess und Müller ${ }^{62}$ ) haben durch den Nachweis der resistenten Innenkörper die Orte des Blutabbaus (vor allem in der Milz) genauer studieren können.

Friedstein und Pappenheim-Suzucki kamen dabei aus dem Vergleich der Wirkung des Blutgiftes in vitro und in vivo zu der klinisch sehr bemerkenswerten Feststellung, daß eine einfach äußere Einwirkung nur єine Gerbung der Oberfläche der Erythrocyten, aber keine Heinzkörperbildung bewirkt, sondern daß zur Entstehung der kompakten Innenkörper eine vitale Zellfunktion anzunehmen ist und daß nur die unter dem Einfluß der Vergiftung neu gebildeten Erythrocyten mit diesen Innenkörpern auftreten. Diese Beobachtung spricht also für eine vitale Funktion der Kapselkörper im Sinne meiner Zelltheorie des Erythrocyten.

Zur Fortsetzung dieser Beobachtungen gebe ich eine kleine Serie von methämoglobinischen Erythrocyten aus dem Blute eines schwer mit Phenylhydrazin vergifteten Meerschweinchens (Taf. III, f). Man sieht in den augenscheinlich reifsten Erythrocyten des kreisenden Blutes die sehr fein auf der Oberfläche verteilten Körnchen, die oben bei Besprechung der $\mathrm{Hb}$.-Strukturen erwähnt wurden. Deutlich jüngere, oft noch etwas polychromatische Blutkörperchen zeigen dagegen bei schwachem allgemeinen Hb.-Gehalt ein kompaktes Körperchen im hellen Hof (Archoplasmastruktur), einige andere zeigen Übergänge in Form von zerbröckelnden gröberen Körperchen. Die Deutung dieser Bilder ist eine doppelte : entweder waren die Substanzen zur Zeit der Einwirkung des Giftes bereits in dieser Lage und wurden nun durch die Gerbwirkung 
des Giftes so fixiert, oder das Gift hemmte bei den jungen Zellen vorübergehend die Verteilung von lipoiden und $\mathrm{Hb}$.-haltigen Substanzen, die sich sonst von den Kapselkörpern distal verteilen. Für diese Auffassung scheinen mir analoge Entstehung von kompakten Zelleinschlüssen im Corneaepithel bei Variola und bei Epithelioma contagiosum zu sprechen, Infektionen, die dort die Ausarbeitung der Hornsubstanzen toxisch stören.

In beiden Erklärungen aber erhalten wir anscheinend einen Einblick in die innere Mechanik der Zelle, die wir beim Erythrocyten nur vom Stand punkt der Zelltheorieaus verstehen können.

Es bleibt nun noch übrig, von dem kleinen dunklen Chromatinkorn zu sprechen, das wir an den Kapselkörpern erwähnten. Es entspricht m. E., wie Dehler ${ }^{64}$ ) im kernhaltigen Erythrocyten, Bremer ${ }^{65}$ ) und Nissle ${ }^{66}$ ) für den kernlosen Erythrocyten richtig annahmen, dem Centroso ma der Zelle, eine Erklärung, die Weidenreich für das von ihm sogar an allen normalen Erythrocyten bestätigte ,Randkörnchen" nicht zugeben wollte. Meinen*) Untersuchungen nach nimmt dieses sonst kaum sichtbare Chromatinkörnchen, das oft schon doppeltist, bei Anämien größere Formen an, erscheintim Ausstrich sogar wie ein bipolares Stäbchen, blau mit dunkelroten Enden bei Giemsafärbung. und kann auch eine kleine blaue homogene oder ringförmige Grund platte a ufweisen, die es äuBerst parasitoid gestaltet. Fine Reihe von tropenmedizinisch wichtigen Pseudoparasiten, wie z. B. Seidelins ${ }^{69}$ ) Paraplasma flavigenum des Gelbfiebers, das Anaplasma Theileri des Küstenfiebers der Rinder, verschiedene Cytorrhyktes-ähnliche Gebilde bei Fleckfieber usw. waren augenscheinlich diesen ,Zentren" so ähnlich, daß ihre Erregernatur dadurch erschüttert wurde. Agramonte ${ }^{67}$ ) bestätigte dies für Gelbfieber, K. F. Meyer ${ }^{68}$ ) für Anaplasmosis. Also auch diese kleinsten Strukturen des Erythrocyten haben pathologische Wichtigkeit, wenn man bedenkt, daß z. B. Seidelin ${ }^{69}$ ) zuerst allein auf Grund des Befundes seiner Erreger im Blut Kranke für Gelbfieberträger ansehen und den bei Gelbfieber bis dahin unbekannten und durch die Epidemiologie nicht bestätigten Be griff des dauernden Parasitenträgers mit seinen weittragenden Konsequenzen aufstellen wollte. Die Zelltheorie des Erythrocyten zeigt uns den Weg zum vergleichenden Studium und zur histologischen Einordnung dieser Gebilde, die sich durchaus mit den bekannten Veränderungen und Vergrößerungen der Zentralapparate während der Regenerationsvorgänge im Epithel- und Bindegewebe deckt. Wahr-

*) Nogu chi entdeckte jetzt eine Spirochäte als Erreger. 
scheinlich wird weiteres Studium dieser Zentren auch die Entstehung der oft beschriebenen Pseudospirochäten aufklären, da die Bildung lebhaft bewegliches geißelartiger Anhänge und ein Abschwimmen der Körnchen im Dunkelfeld bei Anämien leicht zu beobachten ist. Sowohl die Protozoologie wie die Histologie kennt die große Bedeutung der Zentralkörner bei der Geißelbildung (z. B. Spermatogenese). A u ch die fädige Verbindung zum Plättchenkern, die ich im Dunkelfeld wie im Schnellfixationspräparat (Abb. 13) beobachten konnte, entspricht sowohl der Zentrendeutung der Körnchengruppe wie der Kernchenerklärung der Blutplättchen.

Die vorgetragene Zelltheorie des Erythrocyten will und kann kein abgeschlossenes Gebiet sein, im Gegenteil als Arbeitshypothese nur zu einer tieferen Erfassung des Erythrocytenproblems anregen, das für die sichere klinische Verwertung der zahlreichen anämischen Blutbefunde von ausschlaggebender Bedeutung ist.

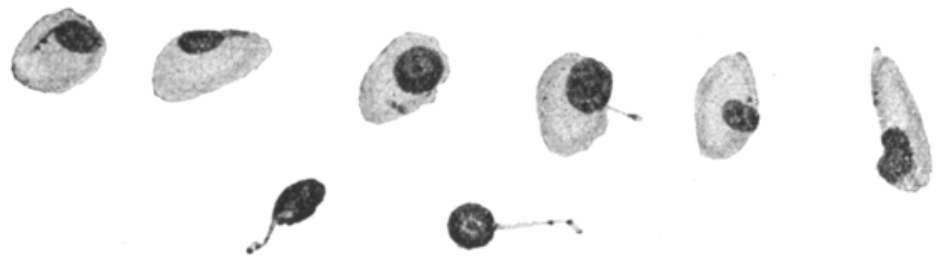

Abb. 13. Plättchenkernige Erythrocyten mit fädigen Verbindungen zur Centrosom-Körnchengruppe. Schnellfxation, Mensch. Hämolytische Anämie bei Lues III.

An neuen Stützbefunden für diese Theorie und ihre klinische Verwertung wurden im Laufe der Arbeit mitgeteilt:

a) Zunahme „Plättchenkerniger“ bei anämischen Zuständen bereits im einfachen Blutplättchenzählpräparat.

b) Pyknotische kernähnliche Blutplättchen im normalen und kranken Blut.

c) Relative und absolute Kurven der Blutplättchen im Vergleich zu den Erythrocytenkurven bei Anämien.

d) Tabellarische Utbersichten der Blutplättchenbefunde in ihrer Beziehung zum übrigen Blutbefund bei anämisierenden Krankheiten mit Vermehrungen oder Verminderungen der Plättchen und gesondert bei Anaemia perniciosa und Purpura.

e) „Zerrissene" Netzsubstanz als Abart der Polychromasie bei toxischen Anämien.

f) Identität polychromer Megalocyten im Ausstrich mit großen blauen Netzen im dicken Tropfen. 


\begin{tabular}{|c|c|c|c|c|c|c|c|c|c|c|c|c|c|c|}
\hline 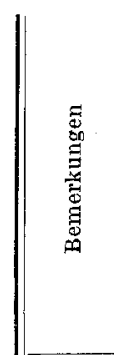 & 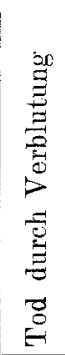 & 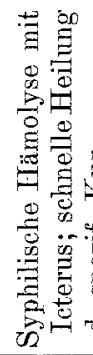 & 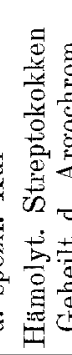 & 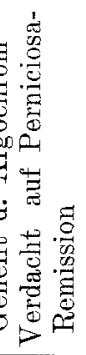 & 递 & 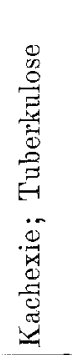 & & 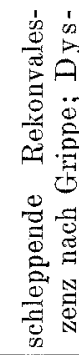 & 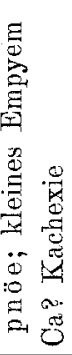 & 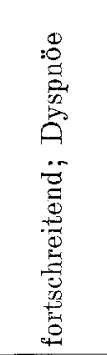 & 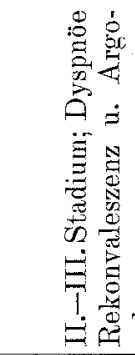 & 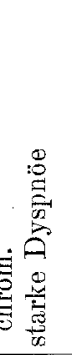 & 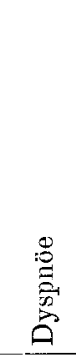 & 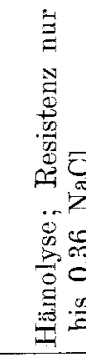 \\
\hline 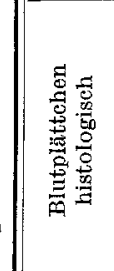 & 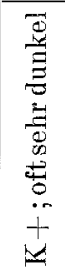 & 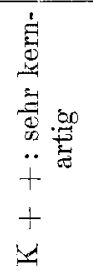 & 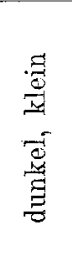 & 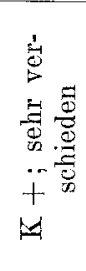 & 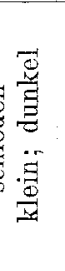 & 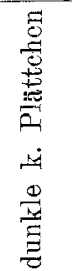 & 1 & 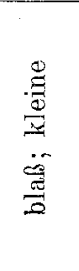 & 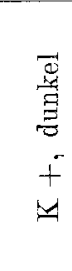 & $\begin{array}{l}4 \\
180 \\
18 \\
0\end{array}$ & & 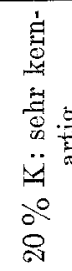 & 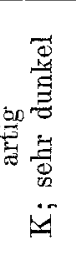 & $\begin{array}{l}5 \\
0 \\
0 \\
0 \\
0 \\
0\end{array}$ \\
\hline 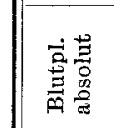 & 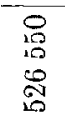 & 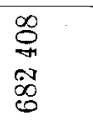 & $\begin{array}{l}8 \\
8 \\
\text { A } \\
\text { in }\end{array}$ & $\begin{array}{l} \\
\\
\infty \\
\infty \\
\infty \\
\infty \\
\infty\end{array}$ & $\begin{array}{l}\frac{8}{6} \\
\frac{8}{0}\end{array}$ & 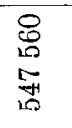 & $\begin{array}{l}0 \\
\frac{2}{\circ} \\
\frac{8}{8}\end{array}$ & 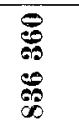 & $\begin{array}{l}8 \\
8 \\
0 \\
80 \\
60 \\
10\end{array}$ & 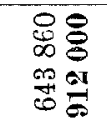 & 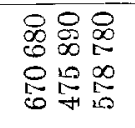 & 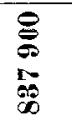 & 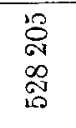 & $\begin{array}{l}8 \\
\infty \\
\infty \\
\mathscr{8} \\
\mathscr{8}\end{array}$ \\
\hline 薑兽 & 8 & $\vec{B}$ & 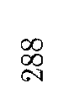 & $\begin{array}{l}\infty \\
\stackrel{\infty}{N}\end{array}$ & 苦 & 落 & 汿 & $\underset{\sim}{\stackrel{\Xi}{*}}$ & ర్ & $\stackrel{\mathscr{g}}{g} \underset{g}{\stackrel{g}{g}}$ & 芯志心 & $\vec{\Xi}$ & $\stackrel{\stackrel{9}{\sharp}}{\sim}$ & F \\
\hline 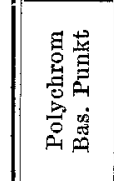 & $\begin{array}{l}+ \\
+ \\
+ \\
+\end{array}$ & $\begin{array}{l}+ \\
+ \\
+ \\
+\end{array}$ & $\begin{array}{l}0 \\
\dot{\theta} \\
+ \\
+ \\
+\end{array}$ & $\begin{array}{l}+ \\
+\end{array}$ & $\begin{array}{l}+ \\
+\end{array}$ & $\begin{array}{l}+ \\
+\end{array}$ & $\begin{array}{l}+ \\
+\end{array}$ & + & I & ++ & & + & \pm & $\begin{array}{l}+ \\
+\end{array}$ \\
\hline 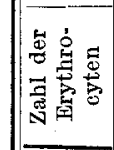 & 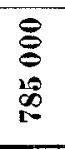 & 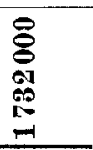 & 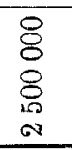 & $\begin{array}{l}8 \\
8 \\
8 \\
\infty \\
-1 \\
\end{array}$ & 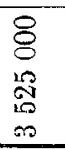 & 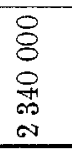 & $\begin{array}{l}8 \\
8 \\
19 \\
7 \\
4 \\
0\end{array}$ & $\begin{array}{l}8 \\
8 \\
8 \\
8 \\
-+1 \\
\end{array}$ & $\begin{array}{l}8 \\
8 \\
0 \\
0 \\
0 \\
0\end{array}$ & 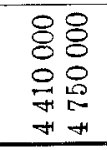 & 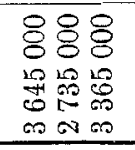 & $\begin{array}{l}8 \\
8 \\
8 \\
8 \\
+ \\
\end{array}$ & $\begin{array}{l}8 \\
8 \\
10 \\
9 \\
0 \\
0\end{array}$ & $\begin{array}{l}8 \\
8 \\
8 \\
8 \\
+1 \\
\end{array}$ \\
\hline 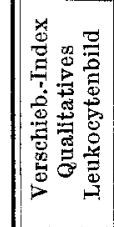 & 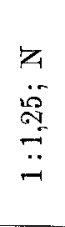 & $\stackrel{\because}{\because}$ & $\ddot{\ddot{0}}$ & $\begin{array}{l}\underline{\theta} \\
\ddot{r} \\
\ddot{r}\end{array}$ & $\begin{array}{l}\not{z} \\
\ddot{0} \\
\ddot{n}\end{array}$ & $\begin{array}{l}z \\
\ddot{z} \\
\ddot{r}\end{array}$ & 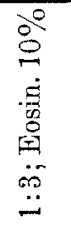 & $\begin{array}{l}z \\
\ddot{a} \\
\ddot{\sim}\end{array}$ & $\begin{array}{l}z \\
\ddot{A} \\
\ddot{-}\end{array}$ & 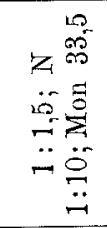 & 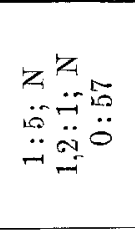 & $\begin{array}{l}z \\
\ddot{m} \\
\ddot{-} \\
\ddot{n}\end{array}$ & $\begin{array}{l}z \\
\ddot{0} \\
\ddot{0}\end{array}$ & $\begin{array}{l}3 \\
\ddot{2} \\
\ddot{2} \\
\ddot{2}\end{array}$ \\
\hline 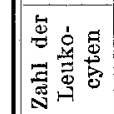 & $\begin{array}{l}8 \\
8 \\
\infty \\
\text { a }\end{array}$ & $\begin{array}{l}8 \\
8 \\
0 \\
0\end{array}$ & $\begin{array}{l}8 \\
8 \\
9\end{array}$ & $\begin{array}{l}8 \\
\\
0 \\
7\end{array}$ & 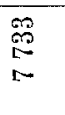 & 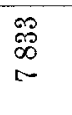 & 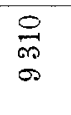 & 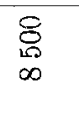 & $\begin{array}{l}8 \\
0 \\
10\end{array}$ & 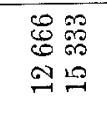 & $\begin{array}{l}088 \\
6: 8 \\
0= \\
0=\end{array}$ & $\begin{array}{l}8 \\
0 \\
10\end{array}$ & $\begin{array}{l}8 \\
8 \\
0 \\
0\end{array}$ & $\begin{array}{l}\mathbb{8} \\
\infty \\
\infty\end{array}$ \\
\hline 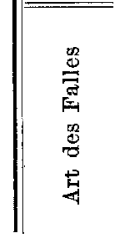 & 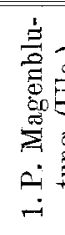 & 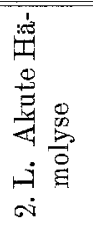 & 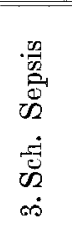 & 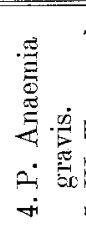 & is & 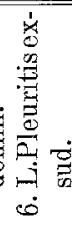 & 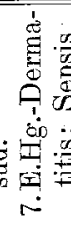 & $\infty$ & . & 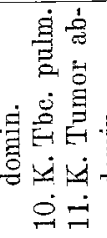 & 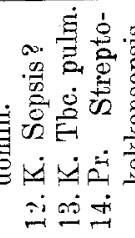 & & 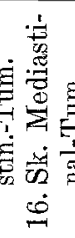 & \\
\hline
\end{tabular}


als Grundlage der klinischen Wertung anämischer Blutbefunde. $\quad 59 \check{~}$
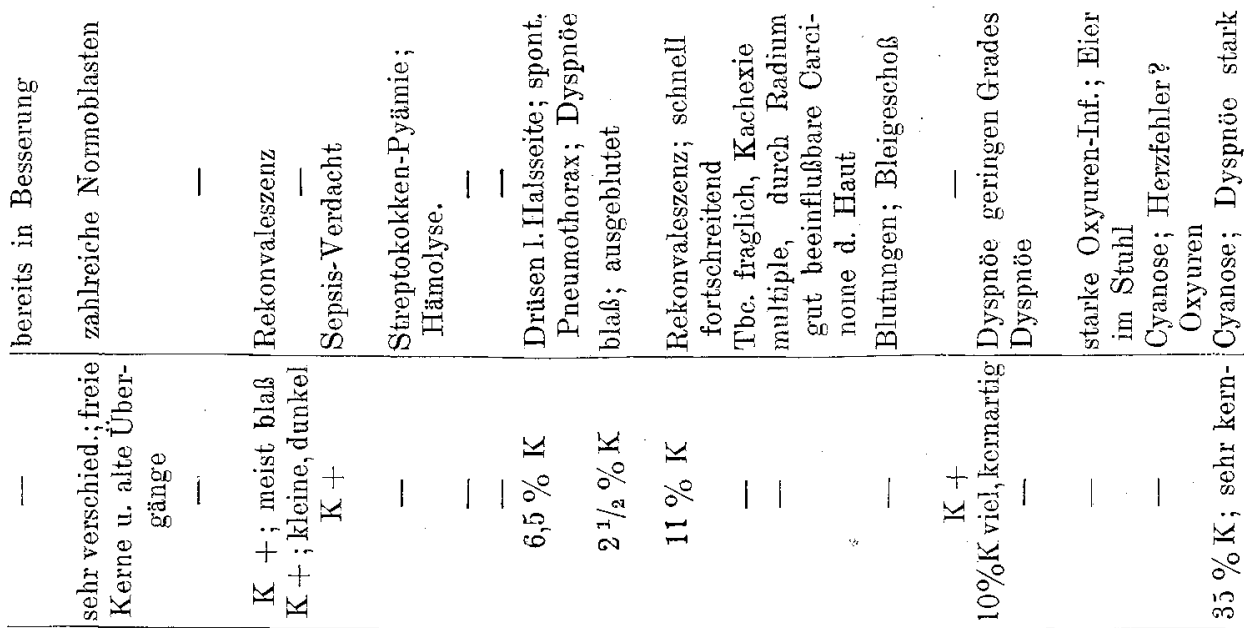

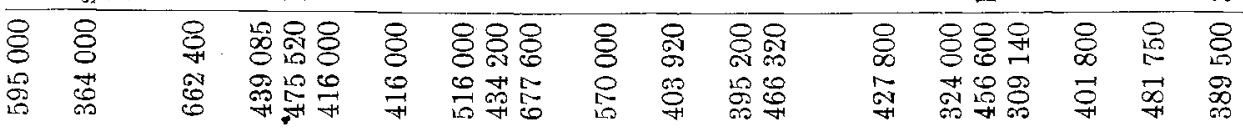

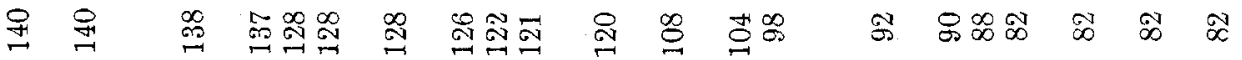

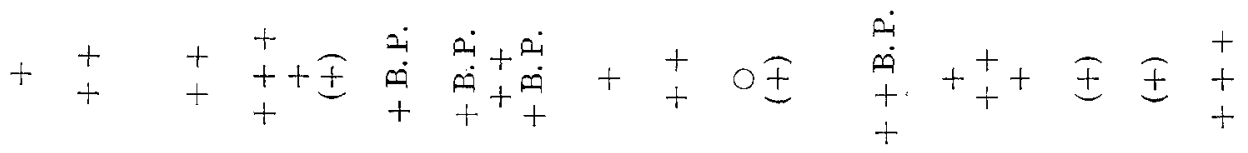

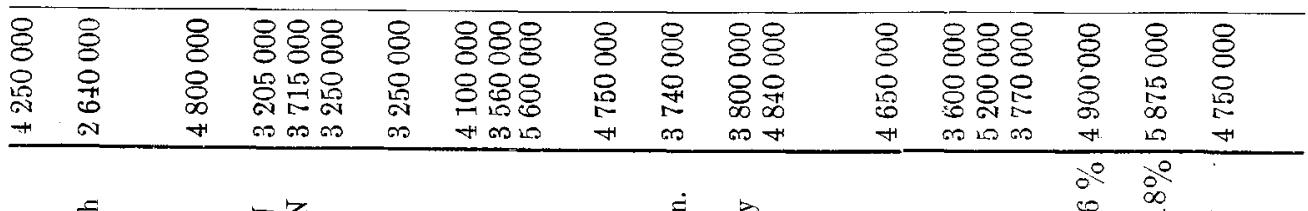

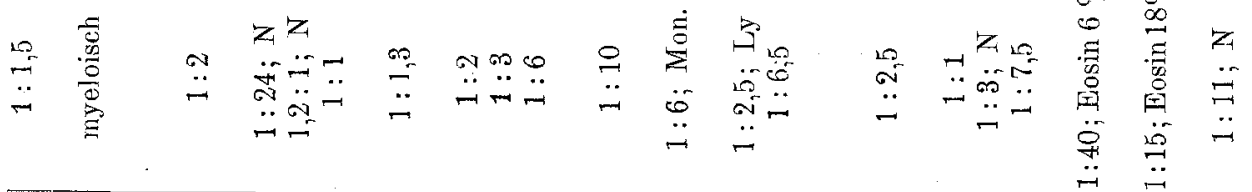

\begin{tabular}{|c|c|c|c|c|c|c|c|c|c|c|c|c|}
\hline 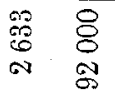 & 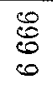 & 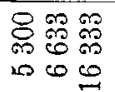 & $\begin{array}{l}\infty \\
\infty \\
\infty \\
\end{array}$ & 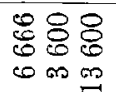 & $\begin{array}{l}60 \\
6 \\
5 \\
0\end{array}$ & $\underset{.8}{8}$ & 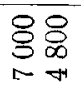 & $\begin{array}{l}8 \\
8 \\
0 \\
0.0\end{array}$ & $\begin{array}{l}8 \\
8 \\
\infty\end{array}$ & $\underset{8}{8}$ & $\stackrel{8}{\infty}$ & $\begin{array}{l}8 \\
8 \\
0\end{array}$ \\
\hline
\end{tabular}

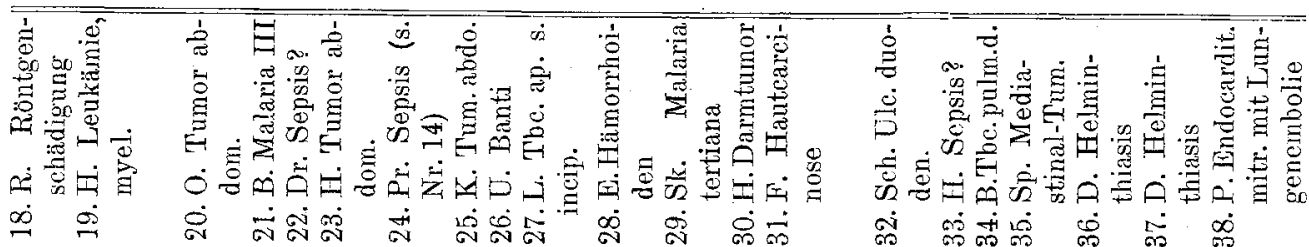


V. Schilling: Die Zelltheorie des Erythrocyten

\begin{tabular}{|c|c|c|c|c|c|c|c|c|c|}
\hline 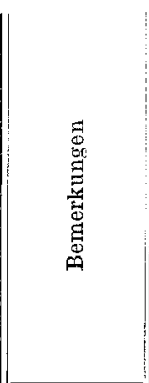 & 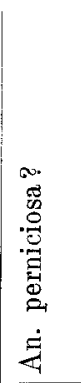 & 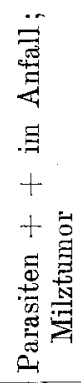 & 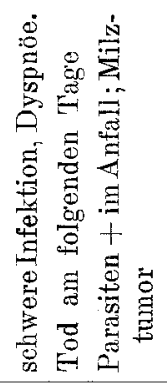 & 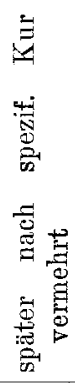 & 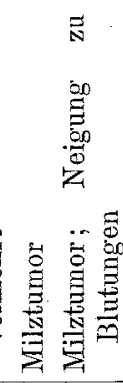 & 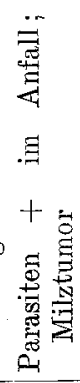 & 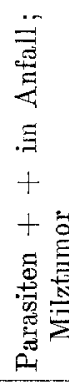 & 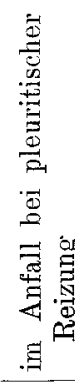 & 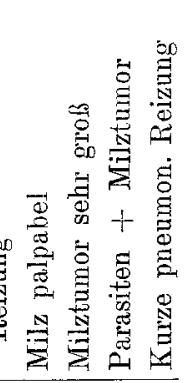 \\
\hline 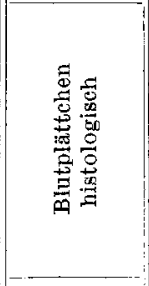 & 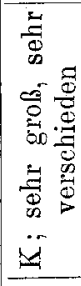 & 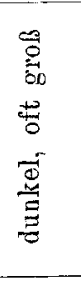 & 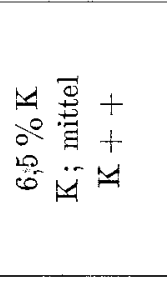 & 1 & 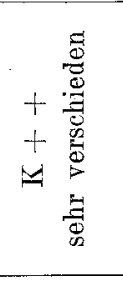 & 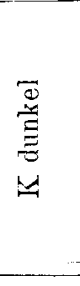 & 1 & I & 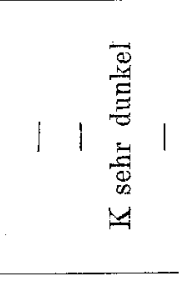 \\
\hline 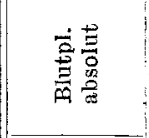 & $\begin{array}{l}8 \\
8 \\
\infty \\
\infty \\
\infty\end{array}$ & 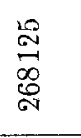 & 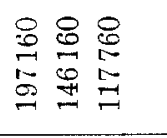 & $\begin{array}{l}\underset{N}{N} \\
\stackrel{N}{\sharp} \\
\text { N }\end{array}$ & $\begin{array}{ll}0 & 8 \\
8 & 8 \\
0 & 0 \\
0 & 8\end{array}$ & $\begin{array}{l}19 \\
18 \\
0 \\
10 \\
60 \\
91\end{array}$ & 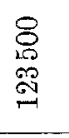 & 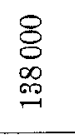 & 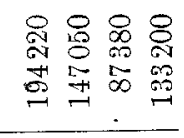 \\
\hline $\begin{array}{c}\text { Blutpl. } \\
: 1000 \text { Ery. }\end{array}$ & $\mathscr{8}$ & 18 & తి $\underset{\forall}{\infty}$ & ึㅏㅂ & 왑 육 & 串 & $\infty$ & $\underset{\pi}{\infty}$ & 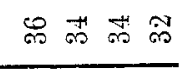 \\
\hline 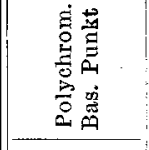 & + & $\begin{array}{l}\dot{\mu} \\
\dot{\rho} \\
+ \\
+\end{array}$ & 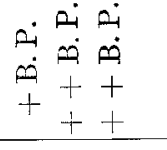 & 1 & $\begin{array}{l}m \\
m+ \\
+\quad+ \\
+ \\
\end{array}$ & I & $\begin{array}{l}+ \\
+\end{array}$ & + & I $\begin{array}{l}\dot{\mu} \\
\dot{+} \\
+\end{array}$ \\
\hline 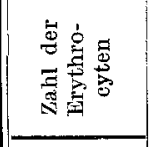 & $\begin{array}{l}8 \\
8 \\
8 \\
8 \\
8 \\
\end{array}$ & \begin{tabular}{l}
8 \\
8 \\
2 \\
\multirow{2}{*}{} \\
+1
\end{tabular} & 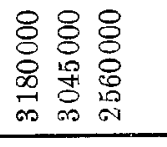 & $\begin{array}{l}8 \\
8 \\
8 \\
10\end{array}$ & $\begin{array}{c}8 \\
8 \\
8 \\
10 \\
0 \\
0 \\
0 \\
\text { m }\end{array}$ & $\begin{array}{l}8 \\
8 \\
10 \\
10 \\
\infty \\
0\end{array}$ & $\begin{array}{l}8 \\
8 \\
0 \\
0 \\
\cdots \\
\cdots \\
0\end{array}$ & $\begin{array}{l}8 \\
8 \\
8 \\
8 \\
\end{array}$ & 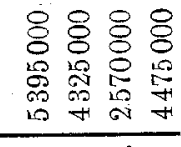 \\
\hline 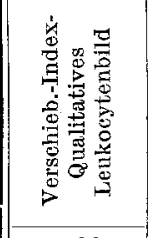 & 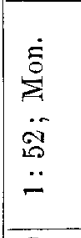 & 1 & 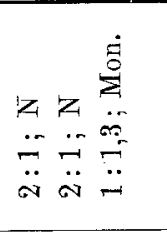 & $\begin{array}{l}\text { 学 } \\
\ddot{0} \\
\ddot{\circ}\end{array}$ & 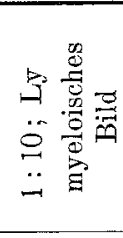 & $\begin{array}{l}\overrightarrow{9} \\
\ddot{\sigma} \\
\ddot{-}\end{array}$ & | & $\begin{array}{l}z \\
\ddot{N} \\
\ddot{\sim}\end{array}$ & 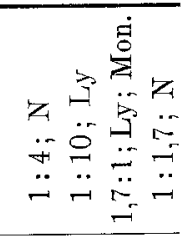 \\
\hline $\begin{array}{c}\text { Zahl } \\
\text { der,Leuko- } \\
\text { cyten } \\
\end{array}$ & 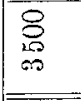 & $\begin{array}{l}8 \\
8 \\
8 \\
0\end{array}$ & $\begin{array}{l}8 \\
8 \\
0 \\
= \\
=\end{array}$ & $\underset{8}{8}$ & 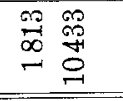 & $\underset{8}{8}$ & 1 & $\stackrel{90}{\square}$ & 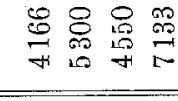 \\
\hline$\sum_{\sum_{i=1}}$ & 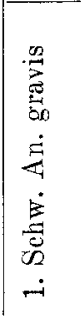 & 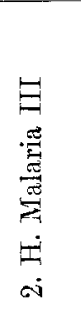 & 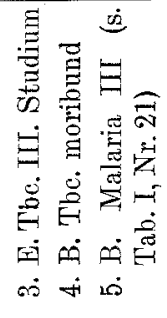 & 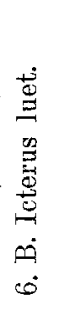 & 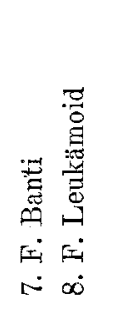 & 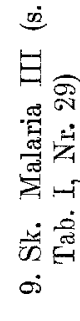 & 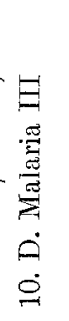 & 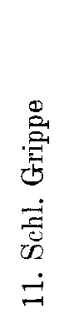 & 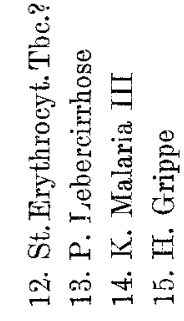 \\
\hline
\end{tabular}


als Grundlage der klinischen Wertung anämischer Blutbefunde.

597

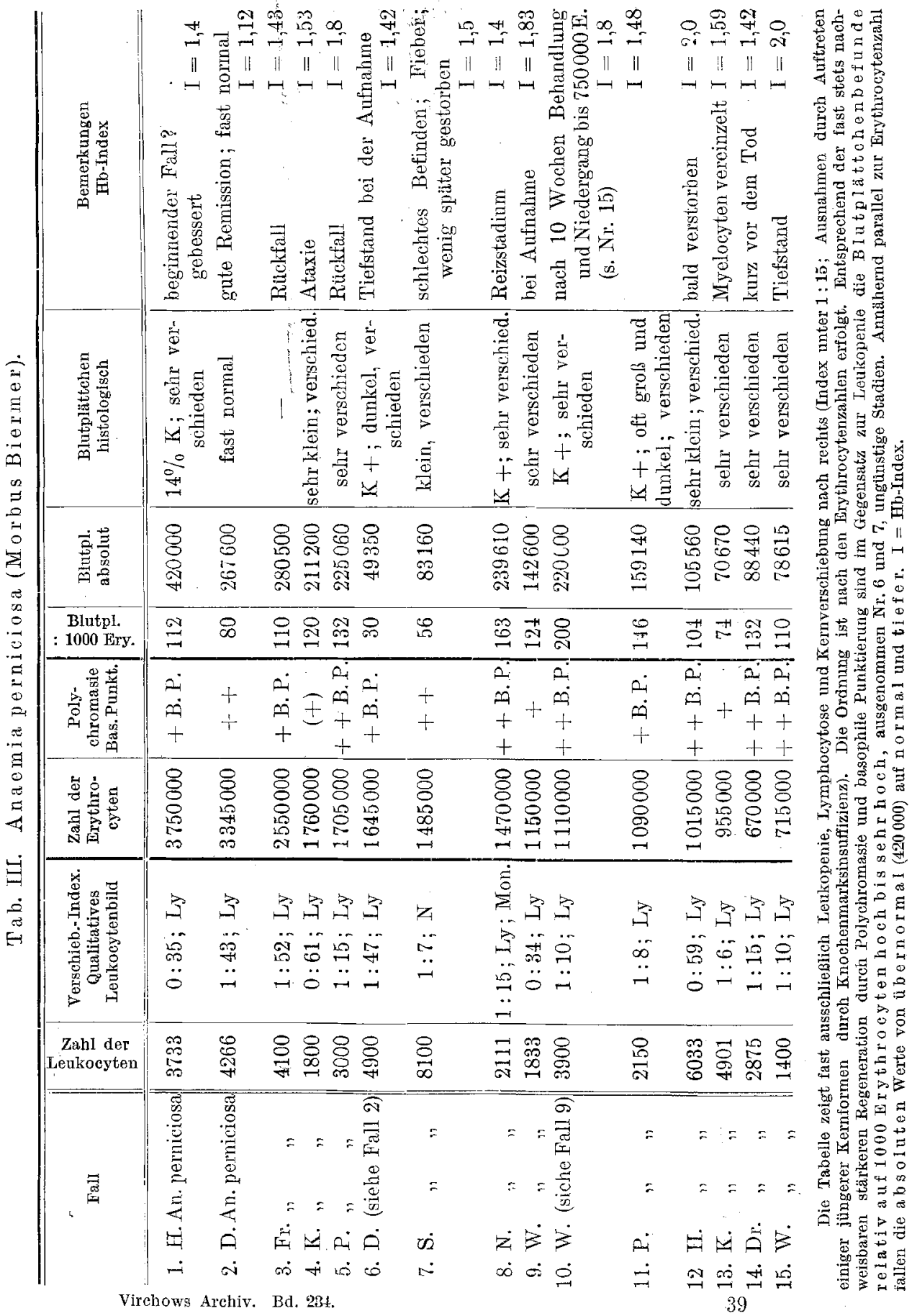




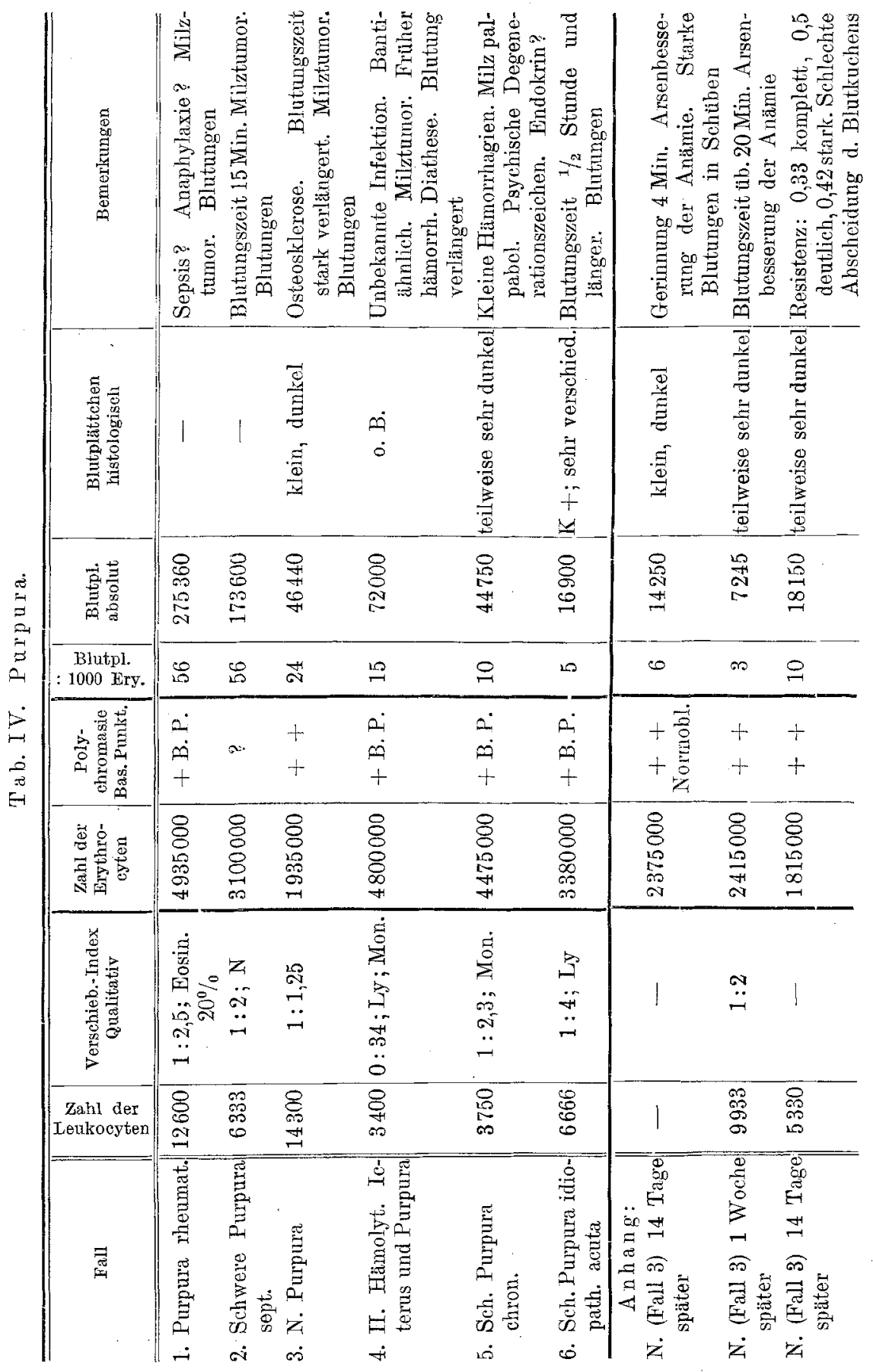


g) Innenkörperdarstellung im Katzenblut durch einfache Giemsahämolyse.

h) Ủbergänge zwischen feinkörnigen oberflächlichen und einliegenden kompakten hämoglobinämischen Innenkörpern und ihre Deutung.

i) Geißelartige Anhänge an Zentralkörnchen und ihre Verbindung mit den Plättchenkernen bei Schnellfixation.

Die Anwendung der Zelltheorie des Erythrocyten ergibt folgende Festlegungen der Erythrocytenstrukturen für die klinische Verwertung.

1. Ist die Kernchentheorie für die Abstammung der Blutplättchen richtig, so sind andere Formen der Entkernung als durch die Umbildung zum Blutplättchen pathologische. Austretende ganze Kerne, Kernzertrümmerungen, Umbildung in Kernkugeln sind nicht physiologische Entkernungen, sondern Anzeichen einer degenerativen Zellschädigung.

2. Weiter ergäbe sich aus der Kernchennatur der Plättchen ihre direkte Beziehung zur Erythropoese. Vermehrungen würden auf Erythroregeneration, Verminderungen auf Hemmung oder Schädigung des erythropoetischen Systemes deuten, soweit für letztere nicht der besondere Prozeß der Thrombolyse heranzuziehen ist (Purpurainfektion u. a.). Anisocytose der Plättchen deutete auf schwerere Schädigung der Entkernung bei Anaemia perniciosa.

3. Die basischen Erythrocyten sind als Träger jugendlichen Spongioplastins gemeinsam als junge Zellen aufzufassen und ihre Entstehung auf degenerativen Wege ist ganz auszuschließen. Die Beobachtung von Netzsubstanz im dicken Tropfen oder in der Vitalfärbung ist klinisch gleichbedeutend mit Polychromasie und entspricht daher im allgemeinen physiologischer Erythroregeneration; dagegen sind ,zerrissene Netzsubstanz" und "basophile Punktierung" klinisch als Schädigung der physiologischen Regeneration zu werten und deuten auf toxische Prozesse.

4. Die Entstehung des megaloblastischen Blutbildes ist biologisch durch celluläre Hypertrophie und Entartung auf dauernde schwere Störung der Erythropoese erklärbar und braucht nicht als eine spezifische embryonale Rückbildung mit absolut perniziöser Bedeutung aufgefaßt zu werden.

5. Die pathologischen Innenkörper der Erythrocyten vom Typus der hämoglobinämischen Innenkörper entwickeln sich durch verschiedenartige Reize in mannigfachen Formen aus gleichen morphologischen Grundstrukturen, den archoplasmatischen Kapselkörpern. Sie bedeuten eine vitale Reaktion der roten Blutzelle auf schädigende Einflüsse und können durch ihren eigenartigen Chemismus wie durch die Möglichkeit ihrer Isolierung tiefere Einblicke in die celluläre Reaktion auf bestimmte Sehädigungen vermitteln. 


\section{Literaturverzeichnis.}

Zusammenfassende Arbeiten: 1) Ehrlich, Charité-Annalen 9. 1884 . 2) $\mathrm{N}$ a egeli, Lehrbuch 1919, 3. Aufl. - $\left.{ }^{3}\right) \mathrm{Pa}$ p penhei m, Morphologische Häma. tologie. Fol. haematol. Orig. 22-23. 1917. - ${ }^{4}$ ) Schilling, V., Arbeiten über den Erythrocyten I-VII. Fol. haematol., Orig. 11 u. 14. 1911/1912. _- 4) S chilling, V., Angewandte Blutlehre f. d. Tropenkrankh. Mense, 2, 2. Aufl. 1914. $\left.{ }^{5}\right) \mathrm{T} \ddot{\mathrm{u}} \mathrm{k}$, Hämatol. Vorlesungen. 2, 1912. $-{ }^{6}$ ) Weidenreich, Die roten Blutkörperchen. Merkel-Bonnets Ergebnisse. 12-14, 1903/04.

Besonders erwähnte Arbeiten: 7) Klieneberger, Dtsch. Arch. f. klin. Med. 126. 1918. Bemerk. Schilling, V., 130. 1919. Erwiderung 130. - ${ }^{8}$ ) Heiden hai n, Plasma und Zelle. II. 1911. - $\left.{ }^{9}\right)$ Sch ur, Münch. med. Wochenschr. 1906. 10) Morris Intern. med. 1909. - ${ }^{11}$ ) Roth, Zeitschr. f. klin. Med. g6. 1912. 12) Hirschfeld, H., Lehrbuch 1918. - 13) Hirschfeld und Weinert, Berl. klin. Wochenschr. 2r. 1917. - ${ }^{14}$ ) Karlb a u , Fol. haematol., Orig. 20. 1916. - ${ }^{1 \bar{s}}$ ) Gra. witz-Grüneberg, Berl. klin. Wochenschr. 1906. - ${ }^{16}$ ) Ferrata und Viglio, Fol. haematol., Orig. 11. 1911. - 17) Maximow, Arch. f. Anat. u. Physiol. Anat. Abtlg. 1899. Arch. f. mikro. Anat. 36. 1910. - ${ }^{18}$ ) Preisich und Heim, Virchows Arch. f. pathol. Anat. u. Physiol. 168. 1904. - 20) Engel, Verein f. Inn. Med. Berlin 1899. Bd. XVIII (I); Anat. Anz. 29. 1906. - ${ }^{21}$ ) Helber, Dtsch. Arch. f. klin. Med. 132. 1905. - 22) Grawitz, Klin. Pathol. d. Blutes. Aufl. 1911. 23) Broeckbank, Med. Chronicle. 1908. - ${ }^{24}$ ) Bizzozero, Virchows Arch. f. pathol. Anat. u. Physiol. 90. 1882. $-{ }^{25}$ ) Wright, Virchows Arch. f. pathol. Anat. u. Physiol. 186. 1906. - ${ }^{26}$ ) Naegeli, Zentralbl. f. allg. Pathol. u. pathol. Anat. 25. 1914. - 27) Oelhafen, Fol. haematol., Orig. 18. 1914. - ${ }^{28}$ ) A ynaud, Monographie. Paris 1909. - ${ }^{29}$ ) Decastello und Meissner, Med. Klinik 11. ${ }^{30}$ ) Bunting, Journ. of exp. med. 11. 1909. - ${ }^{31}$ ) Duke, Journ. of the Americ. med. assoc. 65. 1915. - ${ }^{32}$ ) Frank, Berl. klin. Wochenschr. 1915, 1916, 1917. $\left.{ }^{33}\right)$ Glanzman n, Jahrb. f. Kinderheilk. 83 u. 88. 1916, 1918. - ${ }^{34}$ ) Kaznelson, Dtsch. Arch. f. klin. Med. 122. Dtsch. med. Wochenschr. 1918, H. 5. $\left.-{ }^{34^{2}}\right) \mathrm{K} \mathrm{a} \mathrm{z} \mathrm{-}$ nelson, Zeitschr. f. klin. Med. 8\%. 1919. - ${ }^{35}$ ) Bernhardt, Zieglers Beiträge z. allg. Path. u. pathol. Anat. 55. 1913. - ${ }^{36}$ ) Schilling, V., Dtsch. med. Wochenschr. 1918. - $\left.{ }^{37}\right)$ Fonio, Korrespondenzbl. f. Schweiz. Ärzte 1913, 1915, 1918. ${ }^{38}$ ) Fo nio, Korrespondenzbl. f. Schweiz. Ärzte 1918, S. 1300. - ${ }^{3 y}$ ) Sch midt, R., ref. Fol. haematol. Ref. 19, S. 52. - ${ }^{40}$ ) Ham merschlag, Arch. f. mikroskop. Anat. (i. Druck.)*) — ${ }^{41}$ )Richardson, Med. Research 13. 1905. - ${ }^{42}$ ) Schilling, V., Zeitschr. f. klin. Med. 89, H. 1. 1920. — ${ }^{43}$ ) Darling, Transact. Soc. Trop. med. and hyg. 5. 1910. - ${ }^{44}$ ) Hamburger, Osmot. Druck usw., Bd. I. 1902. 45) Itami und Pratt, Biochem. Zeitschr. 1909. - ${ }^{46}$ ) Rose nthal, Dtsch. med. Wochenschr. 1919; Rosenthal und Patzek, Berl. klin. Wochenschr. 1919. 47) Schilling, V., Münch. med.Wochenschr. S. 230. Feld.B. 1917.-48)König, Fol. haematol., Orig. 9. 1910. — ${ }^{49}$ ) Ferrata, Fol. haematol., Orig. 9. 1910. - 50) Ne greiros - Rinaldi, Morfologia etc. Napoli 1916. - ${ }^{51}$ ) Walterhöffer, Zeitschr. f. klin. Med. 78. - ${ }^{52}$ ) Sch midt, P., Münch. med. Wochenschr. 1903. — ${ }^{53}$ ) Schil ling, V., Fol. haematol., Orig. \%. 1909. - ${ }^{54}$ ) Ma urer, Arch. f. Schiffs- u. Tropenhyg. 14. 1910. - ${ }^{55}$ ) Scha udin n, Arb. a. d. Reichs-Gesundheitsamte 19. 1902. 56) Perroncito, Arch. ital. di biol. 14. 1910. - ${ }^{57}$ ) Friedstein, Fol. haematol., Orig. 12. 1911. - ${ }^{58}$ ) Pappenheim und Suzuki, Fol. haematol., Orig. 13. 1912. - 59) Hartwich, Fol. haematol., Orig. 13. 1912. - ${ }^{60}$ ) K unkel, Fol. haematol., Orig. 14. 1913. - ${ }^{61}$ ) Heuer, Fol. haematol., Orig. 18. 1914. - ${ }^{62}$ ) Hess und Müller, Wien. klin. Wochenschr. 1913. - ${ }^{63}$ ) Müller, H., Zeitschr. f. exp. Path.

*) Jetzt ersehienen 95, 1, 1921 . 
u. Therap. 18. 1916. - ${ }^{64}$ ) Dehler, Arch. f. mikroskop. Anat. 46. 1895. $\left.{ }^{65}\right)$ Bremer, Arch. f. mikroskop. Anat. 45 u. 46. 1895. - ${ }^{66}$ ) Nissle, Arch. f. Hyg. 61. 1907. - ${ }^{67}$ ) Agramonte, Disk. z. Vortrag V. Schilling s. Int. Kongr., Sekt. f. Tropenmed. 1913. - ${ }^{68}$ ) Meyer, F. K., Die perniziöse Anämie der Rinder. Kolle-Wasserma nn. Bd. VII. — ${ }^{69}$ ) Seidelin, Berl. klin. Wochenschr. 1909; Yellow Fever Bureau Bull. 1 u. 2. 1911/13.

\section{Tafelerklärung.}

\section{(Zu Tafel III.)}

a) Blutplättchen-Schnellfixation beim anämisierten Kaninchen. Pipettiermethode mit Dominici-Fixatio und Giemsa - Färbung.

Die Plättchen erscheinen größtenteils als „Plättchenkerne“ typischer Lage und Form. Erythrocyten sind durch Verminderung, Blutplättchen durch Vermehrung zahlenmäßig stark genähert, so daß relativ viele E. ,Plättchenkerne“ enthalten. Rechts Gruppen freier, aber auch kernähnlicher Plättchen (natürliches Ubersichtsbild, nicht gruppiert).

b) Blutplättchen-Schnellfixation bei mensehlicher Anämie $n$ ach schwerer Ruhr. Schalenmethode mit Dominici-Fixation. GiemsaFärbung.

Ausgewählte „Plättchenkernige“ aus einem „Flöckchen“ mit verschiedener Kernlage. Unten natürliche Gruppe von drei Plättchenkernigen nebeneinander und ein austretender Kern mit Gerinnungshäutchen.

c) PolychromeErythrocyten als, Netzfiguren“ im, ,dicken Tropfen"-Präparat. Giemsa-Färbung intensiv.

Bl. Pl. = Blutplättchen. $\mathbf{N}=$ Neutrophiler segmentierter Leukocyt. $\mathrm{M}=$ polychrome Megalocyten. $\mathrm{M}=$ polychromer Megaloblast.

d) unde) Blutplättchentypen aus Fonio-Präparaten. GiemsaFärbung.

Links (d) menschliche leichte Anämie bei Ulc. ventriculi.

Rechts (e) Riesenplättchen einer myeloischen Leukämie. Man beachte die Übergänge von zarter Bläschenform bis zur Ähnlichkeit mit Normoblastenkernen.

f) Serie hämoglobinämischer Innenkörper. Meerschweinchen mit Phenylhydrazin-Vergiftung 0,02 nach 72 Stunden; Ausstrich von Herzblut. Einfache Giemsa-Färbung.

g) und h) Innenkörper im Katzenblut. Hämolytische GiemsaFärbung am unfixierten Ausstrich.

g) Úbersicht, natürliche Lage, nicht gruppiert.

h) Einzelne polychrome Erythrocyten mit Innenkörper und hellem Hof. 

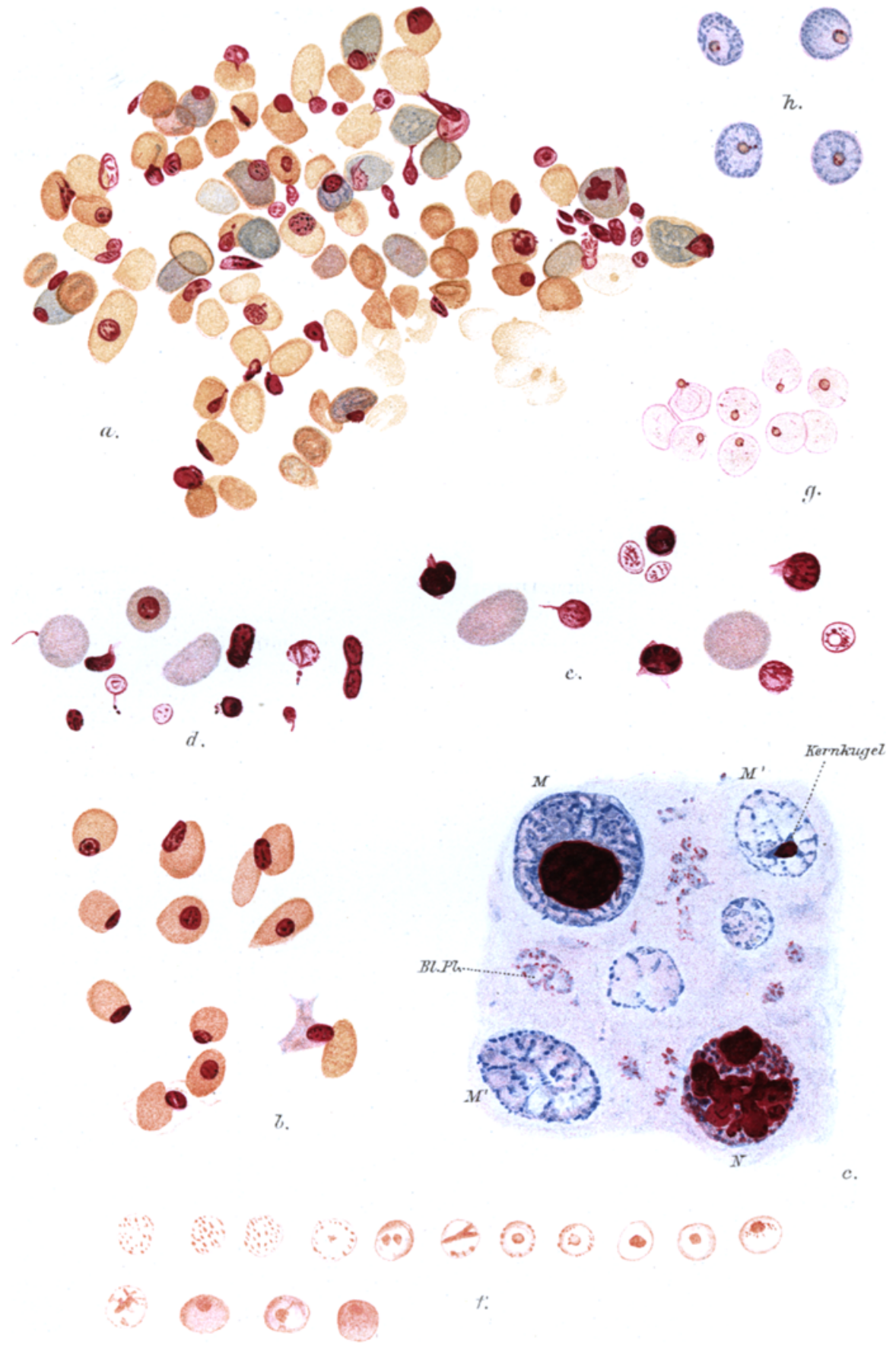